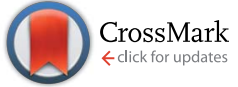

Cite this: Chem. Sci., 2016, 7, 6141

Received 10th March 2016

Accepted 8th June 2016

DOI: $10.1039 / c 6 s c 01120 a$

www.rsc.org/chemicalscience

\section{Palladium-catalyzed regioselective and stereo-invertive ring-opening borylation of 2-arylaziridines with bis(pinacolato)diboron: experimental and computational studies $\dagger$}

\author{
Youhei Takeda, ${ }^{\star a}$ Akinobu Kuroda, ${ }^{a}$ W. M. C. Sameera, ${ }^{\text {b Keiji Morokuma*b }}$ \\ and Satoshi Minakata*a
}

A palladium catalyzed regioselective borylative ring opening reaction of 2 -arylaziridines to give $\beta$-amino- $\beta$ arylethylborates was developed. The reaction reported herein represents the first example of ring-opening borylation of non-vinylic aziridines and direct borylative $\mathrm{C}\left(\mathrm{sp}^{3}\right)-\mathrm{N}$ bond cleavage of neutral organic substrates. NMR studies and density functional theory (DFT) calculations suggested that the active intermediate for the reaction is a $\mathrm{PdL}_{2}$ complex $\left[\mathrm{L}=\mathrm{P}(t-\mathrm{Bu})_{2} \mathrm{Me}\right]$. The multi-component artificial forceinduced reaction method (MC-AFIR) located the transition states for the regioselectivity-determining aziridine ring opening that proceeds in an $\mathrm{S}_{\mathrm{N}} 2$ fashion, and explained the selectivity of the reaction. The full catalytic cycle consists of a selectivity-determining aziridine ring opening (oxidative addition), a proton transfer, phosphine ligand dissociation from the catalyst, boron-boron bond cleavage, and reductive elimination. Water is important to the drive the transmetalation step. The calculated overall mechanism and selectivity are consistent with the experimental results.

\section{Introduction}

Aziridines, three-membered strained azaheterocycles, serve as versatile building blocks in modern organic synthesis. ${ }^{1}$ Regioselective ring opening of aziridines with nucleophiles, which is driven by release of its ring strain, is one of the most useful transformations of aziridines into ubiquitous $\beta$-amino-functionalized motifs. ${ }^{2}$ Aziridines undergo oxidative addition to lowvalent late transition metal complexes at the terminal $\mathrm{C}-\mathrm{N}$ bond in an $\mathrm{S}_{\mathrm{N}} 2$ fashion, generating the corresponding oxidative adducts, azametallacyclobutanes. ${ }^{3-5}$ In light of this reactivity, diverse transition metal-catalyzed regio-, stereo-, and/or chemoselective transformations of aziridines are feasible, ${ }^{6-9}$ where the oxidative addition is smoothly coupled with subsequent elementary processes, such as transmetalation, migratory insertion, and reductive elimination; regioselective $\mathrm{Rh}$ - and Cocatalyzed carbonylative ring expansion of aziridines, pioneered by Alper and co-workers, represent the embodiment of this idea. $^{6}$

${ }^{a}$ Department of Applied Chemistry, Graduate School of Engineering, Osaka University, Yamadaoka 2-1, Suita, Osaka 565-0871, Japan. E-mail: takeda@chem.eng.osaka-u.ac. jp; minakata@chem.eng.osaka-u.ac.jp

${ }^{b}$ Fukui Institute for Fundamental Chemistry, Kyoto University, Takano-Nishihiraki-cho 34-4, Sakyo-ku, Kyoto 606-8103, Japan. E-mail: morokuma.keiji.3a@kyoto-u.ac.jp $\dagger$ Electronic supplementary information (ESI) available: Experimental procedures, spectroscopic data of new compounds, copies of NMR and HPLC charts, and calculation results. See DOI: 10.1039/c6sc01120a
Over the past few years, numerous advances have been made in transition metal-catalyzed ring-opening cross coupling of aziridines, where aziridines can be utilized as a non-classical alkyl electrophilic partner [eqn (1)]. ${ }^{\mathbf{1 0 , 1 1}}$ In 2012, Doyle reported the first Ni-catalyzed regioselective Negishi alkylation of 2-aryl$N$-tosylaziridines that leads to branch-type products via the regioselective cleavage of a benzylic $\mathrm{C}-\mathrm{N}$ bond. ${ }^{\mathbf{1 0} a}$ Since this report, several groups including $\mathrm{us}^{\mathbf{1 1 b}}$ have developed $\mathrm{Ni}^{-10}$ and Pd-catalyzed $^{11}$ regioselective ring-opening cross coupling reactions of aziridines to form $\mathrm{C}\left(\mathrm{sp}^{3}\right)-\mathrm{C}\left(\mathrm{sp}^{2}\right) / \mathrm{C}\left(\mathrm{sp}^{3}\right)$ bonds, with the regioselectivity seemingly governed by the aziridine substrate rather than the catalyst [eqn (1)]. Despite the above-mentioned successes in $\mathrm{C}-\mathrm{C}$ cross couplings, other catalytic ring-opening $\mathrm{C}-\mathrm{E}(\mathrm{E} \neq \mathrm{C})$ bond forming reactions of aziridines based on a cross-coupling mechanism are also unexploited. ${ }^{12}$

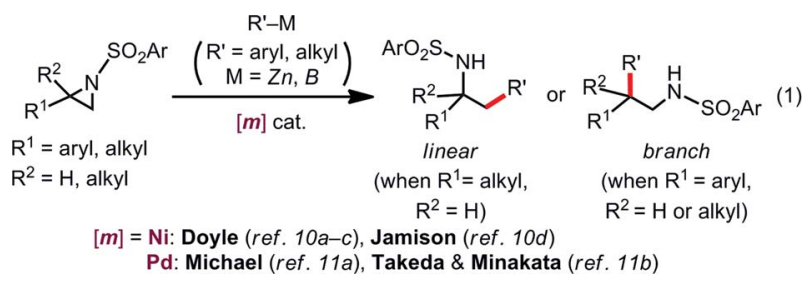

Our latest findings ${ }^{11 b}$ led us to seek new catalytic ringopening $\mathrm{C}-\mathrm{E}$ coupling systems of aziridines. Moreover, we became intrigued with the $\mathrm{C}-\mathrm{B}$ coupling of aziridines to give $\beta$ amino-functionalized alkylboronates; alkylboronic acid 
derivatives serve not only as useful building blocks in organic synthesis, but are also biologically interesting motifs in medicinal chemistry. ${ }^{13}$ Only a few precedents in transitionmetal-catalyzed borylative substitution of vinylaziridines via $\mathrm{C}\left(\mathrm{sp}^{3}\right)-\mathrm{N}$ bond cleavage have been reported. Szabó and Pineschi disclosed a $\mathrm{Pd}(\mathrm{II})$ pincer complex ${ }^{14}$ and a Ni(0)/BINAP ${ }^{12}$ system as catalysts for the borylative ring opening of vinylaziridines with diboron reagents via the cleavage of an allylic $\mathrm{C}-\mathrm{N}$ bond to give $\gamma$-amino alkylboronic acid derivatives (formal $\mathrm{S}_{\mathrm{N}} 2^{\prime}$-type reaction), ${ }^{15}$ respectively [eqn (2)]. Nevertheless, to the best of our knowledge, the catalytic direct displacement of the $\mathrm{C}\left(\mathrm{sp}^{3}\right)-\mathrm{N}$ bond of aziridines with a $\mathrm{C}\left(\mathrm{sp}^{3}\right)-\mathrm{B}$ bond on the same carbon (formal $\mathrm{S}_{\mathrm{N}}$ 2-type reaction) has never been described to date.

We herein report a regioselective ring-opening $\mathrm{C}-\mathrm{B}$ crosscoupling reaction of 2-arylaziridines that is realized using a $\mathrm{Pd} / \mathrm{P}(t-\mathrm{Bu})_{2} \mathrm{Me} / \mathrm{bpy}$ catalytic system to give $\beta$-amino-alkylboronates [eqn (3)], which can serve as versatile building blocks to synthesize amino-functionalized compounds and biologically relevant $\beta$-amino acid surrogates. ${ }^{16,17}$ Notably, our reaction features the opposite regioselectivity in $\mathrm{C}-\mathrm{N}$ bond cleavage (at the 3-position) to those previously reported for $\mathrm{C}-\mathrm{C}$ cross couplings using the same type of aziridine substrate (at the 2-position). ${ }^{\mathbf{1 0 a}, \boldsymbol{c}, \mathbf{1 1 b}}$ Also, our C-B coupling system represents the first example of a formal $\mathrm{S}_{\mathrm{N}} 2$-type borylative $\mathrm{C}\left(\mathrm{sp}^{3}\right)-\mathrm{N}$ bond cleavage of neutral compounds. ${ }^{18}$ It should be noted that the present C-B coupling proceeds smoothly under neutral conditions as in the cases of borylative substitution of allyl carboxylates ${ }^{19}$ and carbonates. ${ }^{19 a, 20}$ In these cases, the leaving groupderived oxy anions $\left(\mathrm{RCO}_{2}{ }^{-}\right.$and $\left.\mathrm{RO}^{-}\right)$serve as the internal bases, while the metal catalyzed borylative substitution of alkyl halides usually requires the addition of stoichiometric external base or activator to promote transmetalation. ${ }^{21}$ In addition to experimental elaboration, we have performed theoretical calculations, applying density functional theory (DFT) and the multicomponent artificial force-induced reaction (MC-AFIR) method to determine the mechanism of the reaction and explain the origin of the selectivity, and to clarify why external base is not required in this reaction system.

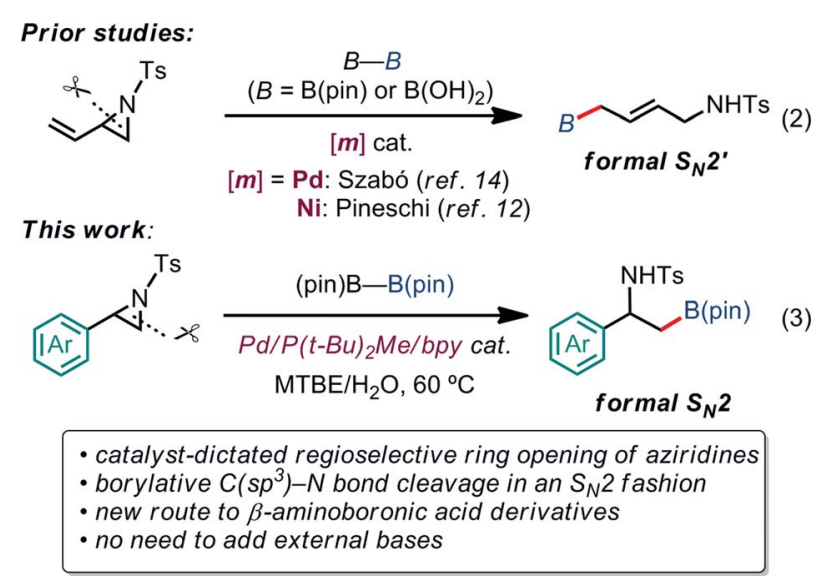

\section{Results and discussion}

\section{Experimental part}

Development of Pd-catalyzed borylative ring-opening reaction of 2-arylaziridines. To identify the reaction conditions for the borylative ring-opening reaction, optimization studies applying racemic 2-phenyl- $N$-tosyl-aziridines (1a) as a model substrate with bis(pinacolato)diboron $\mathrm{B}_{2}(\mathrm{pin})_{2}$ (2) were performed (Tables S1-S13 in the ESI $\dagger$ ). ${ }^{22}$ The executive summary of the optimization study is shown in Table 1.

The highest yield (81\%, isolated yield: $71 \%)$ of borylated product 3a was obtained when 1a was treated with 1.2 equiv. of $\mathrm{B}_{2}$ (pin) $)_{2}$ at $60^{\circ} \mathrm{C}$ in the presence of catalytic amounts of $\mathrm{Cp}$ (allyl) $\mathrm{Pd}(2 \mathrm{~mol} \%), \mathrm{P}(t-\mathrm{Bu})_{2} \mathrm{Me}^{23}$ (1 mol\%), and 2,2'-bipyridine (bpy, 20 $\mathrm{mol} \%$ ) in a mixed solvent of methyl-tert-butylether (MTBE) and $\mathrm{H}_{2} \mathrm{O}$ (entry 1, "standard conditions"). Most importantly, the regioselectivity of this ring opening and $\mathrm{C}-\mathrm{B}$ coupling was opposite to those observed with the $\mathrm{C}-\mathrm{C}$ coupling of the same substrate, ${ }^{\mathbf{1 0 a}, \boldsymbol{c}, \mathbf{1 1 b}}$ implying that the oxidative addition occurred at the $\mathrm{C}-\mathrm{N}$ bond on the terminal carbon (the 3-position of the aziridine). The regioisomer of 3a was not detected in the crude ${ }^{1} \mathrm{H}$ NMR spectra, indicating that the regioselectivity in the ringopening of 1a should be almost perfect. In fact, the regioselective oxidative addition dictated by the interactions between the substrate and the $\operatorname{Pd}(0)$ catalyst was supported by theoretical calculations (vide infra). The $\mathrm{L}: \mathrm{Pd}$ ratio $\left[\mathrm{L}=\mathrm{P}(t-\mathrm{Bu})_{2} \mathrm{Me}\right]$ was found to have a significant impact on the product distribution (entries 2 and 3). As the $\mathrm{L}$ : Pd ratio was increased from 0.5 (entry 1) to 2 to 3 , the yields of 3 a decreased to $74 \%$ and $45 \%$, respectively (entries 2 and 3). This irregular ratio of $\mathrm{L}: \mathrm{Pd}$ implies that there might be a complex equilibrium of $\mathrm{PdL}_{n}$ species generated in situ, some of which are specifically active in the catalytic cycle. In fact, this speculation was partly supported with ${ }^{31} \mathrm{P}$ NMR experiments and theoretical calculations (vide infra). Addition of electron deficient unsaturated compounds, which can coordinate to metal complexes, is an effective strategy to suppress undesired $\beta$-hydride elimination or to accelerate reductive elimination, thereby often leading to better results in alkyl cross coupling reactions. ${ }^{24}$ Indeed, the effect of adding bpy was significantly effective for suppressing the formation of byproduct 6 as well as 5, which was presumably derived from the hydrolysis of 6 with $\mathrm{H}_{2} \mathrm{O}$ (entries 4-7). The effect of the ligands was also significant (entries 8-10). $\mathrm{N}$ heterocyclic carbene (NHC) ligands, SIPr for instance, ${ }^{11 b}$ promoted the consumption of $\mathbf{1 a}$ and produced undesired products 4 and $\mathbf{5}$ (entry 8). The results obtained from sterically demanding trialkylphosphine/Pd catalysts (entries 9 and 10) suggest a sluggish oxidative addition step, which is in good agreement with Wolfe's report. ${ }^{9}$ Furthermore, as mentioned in the introduction section, the ring opening borylation disclosed herein does not require the addition of any external base, which is usually used to activate the transmetalation step for the borylative substitution of alkyl halides. In connection with this, addition of water is crucial. Moreover, in the absence of $\mathrm{H}_{2} \mathrm{O}$, no conversion of 1a was observed (entry 11), while at least 1 equiv. of $\mathrm{H}_{2} \mathrm{O}$ allowed the borylation (Table $\mathrm{S} 11$ in the ESI $\dagger$ ). 


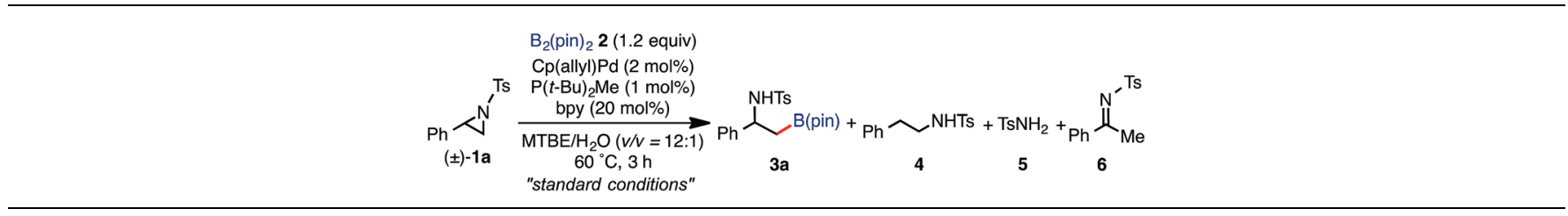

\begin{tabular}{|c|c|c|c|c|c|c|}
\hline \multirow[b]{2}{*}{ Entry } & \multirow[b]{2}{*}{ Difference from the "standard conditions" } & \multicolumn{4}{|c|}{ Yield $^{a}(\%)$} & \multirow[b]{2}{*}{ Recovery of $1 \mathbf{a}^{a}(\%)$} \\
\hline & & $3 a$ & 4 & 5 & 6 & \\
\hline 1 & None & 81 & 0 & 0 & 13 & 0 \\
\hline 2 & Cp(allyl)Pd $(1 \mathrm{~mol} \%) / \mathrm{P}(t-\mathrm{Bu})_{2} \mathrm{Me}(2 \mathrm{~mol} \%)$ & 74 & 0 & 11 & 12 & 3 \\
\hline 3 & $\mathrm{Cp}$ (allyl)Pd $(1 \mathrm{~mol} \%) / \mathrm{P}(t-\mathrm{Bu})_{2} \mathrm{Me}(3 \mathrm{~mol} \%)$ & 45 & 0 & 10 & 14 & 0 \\
\hline $4^{b}$ & Without bpy & 52 & 0 & 14 & 25 & 0 \\
\hline $5^{b}$ & $\begin{array}{l}\mathrm{MeO}_{2} \mathrm{C} \leadsto \mathrm{CO}_{2} \mathrm{Me} \text { instead of bpy } \\
(10 \mathrm{~mol} \%)\end{array}$ & 0 & 0 & 10 & 0 & 90 \\
\hline $6^{b}$ & instead of bpy & Trace & 0 & 3 & 0 & 96 \\
\hline $7^{b}$ & (5 mol\%) & 64 & 0 & 8 & 16 & 0 \\
\hline 8 & $\mathrm{Pd}_{2}(\mathrm{dba})_{3} / \mathrm{SIPr}$ was used as catalyst & 0 & 5 & 37 & 0 & 48 \\
\hline 9 & $\mathrm{Pd}_{2}(\mathrm{dba})_{3} / \mathrm{PCy}_{3}$ was used as catalyst & 5 & 10 & 0 & 0 & 85 \\
\hline 10 & $\mathrm{Pd}\left[\mathrm{P}(t-\mathrm{Bu})_{3}\right]_{2}$ was used as catalyst & 0 & 0 & 0 & 0 & 97 \\
\hline $11^{c}$ & Without $\mathrm{H}_{2} \mathrm{O}$ & 0 & 0 & 0 & 7 & 84 \\
\hline
\end{tabular}

${ }^{a}$ Determined with GC or ${ }^{1} \mathrm{H}$ NMR. ${ }^{b} 1 \mathrm{~mol} \%$ of Cp(allyl)Pd and 2 mol\% of ligand were used. ${ }^{c} 1$ mol\% of Cp(allyl)Pd and 0.5 mol\% of ligand were used.

Theoretical calculations implied that $\mathrm{H}_{2} \mathrm{O}$ serves as a proton source $\left(\mathrm{H}^{+}\right)$as well as a source of internal base $(\mathrm{Pd}-\mathrm{OH})$ to promote the four-membered transmetalation between $\mathrm{B}_{2}(\mathrm{pin})_{2}$ and Pd (vide infra). To investigate the fate of the other $\mathrm{B}$ (pin) moiety of $B_{2}(\text { pin })_{2}$ in the reaction, the ${ }^{11} \mathrm{~B}$ NMR spectrum of the crude product was acquired in benzene- $d_{6}$. The only peak other than the remaining $\mathrm{B}_{2}(\mathrm{pin})_{2}$ was detected at $\delta=22.6 \mathrm{ppm}$ as a slightly broad singlet. The comparison with the reported ${ }^{11} \mathrm{~B}$ resonances of (pin)B-OH $\left(\delta=22.5 \text { ppm in benzene- } d_{6}\right)^{25 a}$ and (pin)B-O-B(pin) $\left(\delta=21.6 \text { ppm in benzene- } d_{6}\right)^{25 b}$ would suggest that one of the $\mathrm{B}(\mathrm{pin})$ moieties of the starting diboron reagent was converted to (pin)B-OH during the reaction.

Substrate scope and synthetic utility. After establishing the optimized conditions, we explored the substrate scope of the borylative substitution reaction (Table 2). In terms of 2-arylaziridines, $p$-, $m$-, and $o$-tolyl-substituted aziridines $2 \mathbf{b}, \mathbf{2 c}$, and $2 d$ smoothly underwent borylative ring opening in a regioselective manner to give the corresponding $\beta$-amide- $\beta$-tolylethylboronates $\mathbf{3 b}, \mathbf{3 c}$, and $\mathbf{3 d}$ in good yields. Aziridine bearing a $p$-fluorophenyl substituent at the 2-position was efficiently borylated, giving the corresponding alkylboronate $\mathbf{3 e}$ in a high yield. It is important to note that the $p$-Cl functionality on the aryl ring of aziridine $2 \mathrm{f}$ survived the reaction conditions to provide the borylative product $\mathbf{3 f}$ in a high yield. Nevertheless, the reaction with $p$-bromophenyl-substituted aziridine did not proceed at all. An invaluable functional group in medicinal chemistry, a $\mathrm{CF}_{3}$-installed aziridine $\mathbf{2} \mathbf{g}$ gave the corresponding
$\mathrm{CF}_{3}$-bearing alkylboronate $3 \mathrm{~g}$. Notably, this ring opening borylation was applicable to the arylaziridines bearing a strong electron withdrawing group $\left(\mathrm{NO}_{2}\right.$, OAc, and $\left.\mathrm{CO}_{2} \mathrm{Me}\right)$, and kept these functionalities intact. This highlights an advantage of using neutral conditions.

Furthermore, the borylation was scalable, and 3a was prepared on a gram scale $(2.89 \mathrm{~g}, 72 \%$ yield $)$ from $10 \mathrm{mmol}$ of $\mathbf{1 a}$ (pS17 of the ESI $\dagger$ ). With respect to the limitation of substrate, 2pyridyl- (1k) and 2-alkylaziridines (11, 1m, and 1n) were not consumed under the reaction conditions. Furthermore, this reaction is very sensitive to the steric hindrance around the 3positioned carbon, where oxidative addition to $\operatorname{Pd}(0)$ has occurred. For example, 2-methyl-2-phenylaziridine (10) and trans-2-phenyl-3-methylaziridine (1p) were not consumed at all under the standard conditions. As for the scope of the $N$-functional groups of aziridines, $p$ - $\mathrm{MeOC}_{6} \mathrm{H}_{4} \mathrm{SO}_{2}$ and $t-\mathrm{BuSO}_{2}$ substituted 2-phenylaziridines smoothly underwent borylation in a regioselective manner (at the 3-position) to produce the corresponding $\beta$-amino- $\beta$-phenylethylboronates $3 \mathbf{r}(65 \%)$ and 3 s $(52 \%)$, respectively. On the other hand, $N$ - $p$-nosyl-2-phenylaziridine did not give borylated product (Table S12 in the ESI $\dagger$ ). The use of an $N$-acylated aziridine, $N$-Boc-2-phenylaziridine for instance, did not give borylated products at a noticeable level, highlighting the efficacy of the $N$-tosyl group for the borylation. Regarding the diboron reagents, the use of bis(neopentyl glycolato)diboron gave the corresponding aminoboronate product $\left(\mathbf{3 a}^{\prime}\right)$ in $39 \%$ yield, while the borylation using bis(hexylene 
Table 2 Scope and limitation of the borylation ${ }^{a, b}$
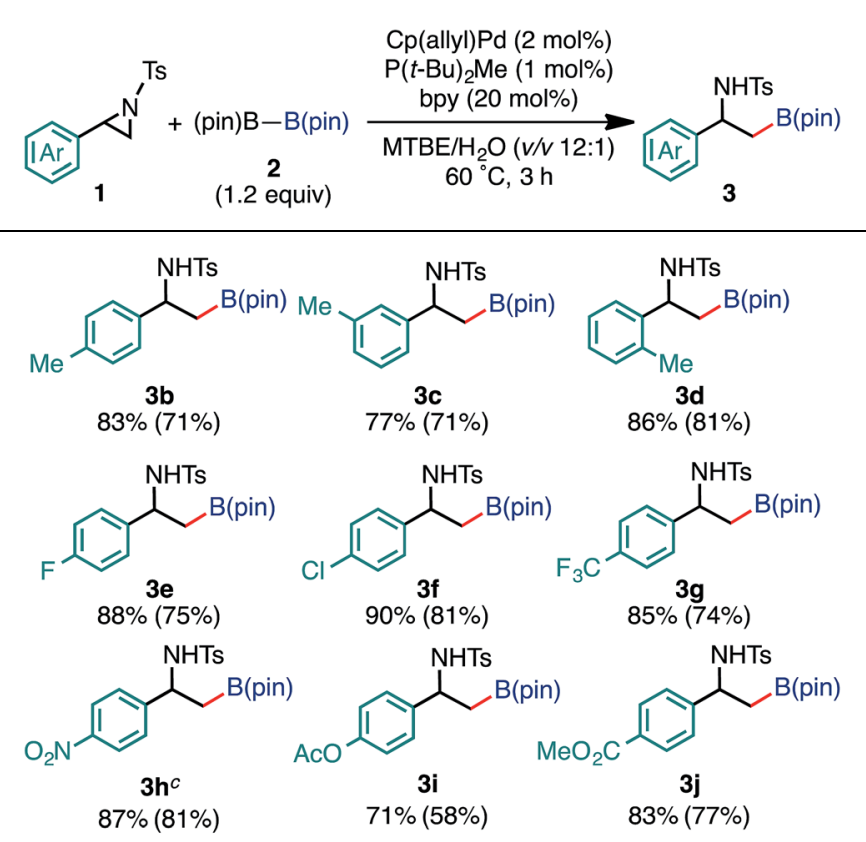

\section{No Reaction with}
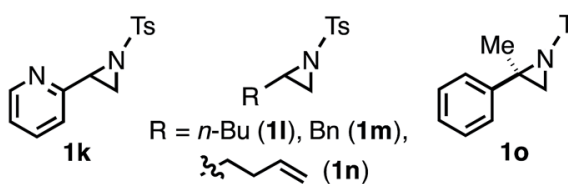

10

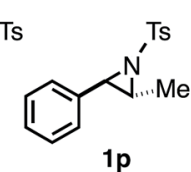

$1 p$

\begin{abstract}
${ }^{a}$ Reaction conditions: 1 (0.50 mmol), 2 (0.60 mmol), Cp(allyl)Pd $(10 \mu \mathrm{mol}), \mathrm{P}(t-\mathrm{Bu})_{2} \mathrm{Me}(5 \mu \mathrm{mol})$, bpy $(10 \mu \mathrm{mol})$ in $\mathrm{MTBE} / \mathrm{H}_{2} \mathrm{O}(1.5 \mathrm{~mL}$, $\mathrm{v} / \mathrm{v} 12: 1$ ) at $60{ }^{\circ} \mathrm{C}$ under $\mathrm{N}_{2}$ atmosphere for $3 \mathrm{~h}$. ${ }^{b}$ The values outside and inside parentheses indicate ${ }^{1} \mathrm{H}$ NMR and isolated yields, respectively. ${ }^{c}$ The reaction was conducted at $80{ }^{\circ} \mathrm{C}$.
\end{abstract}

glycolato)diboron produced the corresponding borylated products in a low yield as an inseparable diastereomeric mixture, presumably due to the existence of two chiral centers on the benzylic and glycolate carbons (Table S13 in the ESI†).

Borylated product 3a was successfully transformed into $\beta$ amino- $\beta$-aryl-substituted alkyltrifluoroborate 7 in excellent yield, which can serve as a versatile building block to synthesize $\beta$-amino- $\beta$-arylethanes through $\mathrm{Pd}$-catalyzed cross coupling reactions [eqn (4)]. ${ }^{26}$

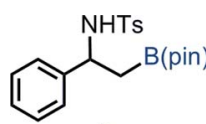

$3 a$

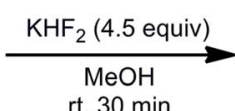

rt, 30 min

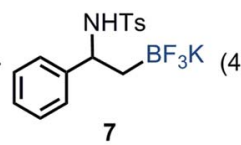

$94 \%$

In order to understand the stereochemical outcome of the secondary stereogenic center of the borylated product and to demonstrate the utility of the alkylboronate, an enantiopure aziridine $(R)$-1a (99\% ee from chiral HPLC analysis) was subjected to the standard reaction conditions (Scheme 1). HPLC analysis of the borylated product $3 \mathbf{a}$ revealed that the stereochemical information was completely retained (99\% ee, $S$ ) through the reaction. This result excludes the possibility of the reaction pathway of oxidative addition/ $\beta$-hydride elimination/ re-insertion of $[\mathrm{Pd}-\mathrm{H}]$ species leading to $3 \mathrm{a}$, although it cannot perfectly exclude such a pathway. ${ }^{27}$ To demonstrate the synthetic utility of the enantiopure $\beta$-amino-alkylboronate $(S)$ 3a, the asymmetric synthesis of 3-phenyl-1,2,3,4-tetrahydroisoquinoline derivative was conducted (Scheme 1). The tetrahydroisoquinoline skeleton is a ubiquitous motif in alkaloid natural products and constitutes a biologically important azaheterocycle. ${ }^{28}$ Enantiopure alkylboronate $(S)$-3a was subjected to the Pd-catalyzed Suzuki-Miyaura cross coupling ${ }^{29}$ with chlorobenzene to give the optically active 1,2-diphenylamine derivative $(S)-8$ in $69 \%$ yield, while keeping the enantiopurity intact (99\% ee, chiral HPLC). The following Pictet-Spengler reaction ${ }^{30}$ successfully gave the enantiopure tetrahydroisoquinoline product $(S)-9$ in excellent yield.

Mechanistic aspect. To obtain the stereochemical course in the oxidative addition step, a similar synthetic sequence using deuterated aziridine $c i s-\mathbf{1 a}-d_{1}$ as a substrate was conducted (Scheme 2). The stereochemistry on the terminal carbon (the 3position) was completely inverted (for details, see the $\operatorname{ESI} \dagger$ ). This result agrees with the $\mathrm{S}_{\mathrm{N}} 2$ nature of the oxidative addition process of aziridine toward $\operatorname{Pd}(0)$ complexes reported by our group $^{11 b}$ and others. ${ }^{5,11 a}$ Moreover, this stereo-invertive process is supported with computational studies (vide infra).

To identify the Pd species generated by mixing $\mathrm{P}(t-\mathrm{Bu})_{2} \mathrm{Me}$ and $\mathrm{Cp}$ (allyl)Pd, we monitored the ${ }^{31} \mathrm{P}\left\{{ }^{1} \mathrm{H}\right\}$ NMR spectra of these mixtures in THF- $d_{8}$ at $60{ }^{\circ} \mathrm{C}$ (Fig. 1). Upon addition of 2 equiv. of $\mathrm{Cp}($ allyl)Pd to $\mathrm{L}$ (i.e., $\mathrm{L}: \mathrm{Pd}=0.5$ ), the sharp resonance corresponding to free L at $\delta 15.3$ ppm (Fig. 1a, lit. $\delta 12.5 \mathrm{ppm}$ at room temperature in toluene- $\left.d_{8}\right),{ }^{31}$ completely disappeared and three new peaks appeared at $\delta 37.0$ (sharp, strong), 44.7 (broad, weak), and 62.0 (broad, weak) ppm (Fig. 1b). According to the data reported by the Baird group, ${ }^{32}$ these peaks are assignable to a dinuclear $\mathrm{Pd}(\mathrm{I})$ complex $\left[\mathrm{Pd}_{2} \mathrm{~L}_{2}(\mu\right.$-Cp) $(\mu$-allyl)] (lit. $\delta 35.4 \mathrm{ppm}$ at $65{ }^{\circ} \mathrm{C}$ in toluene- $d_{8}$ ), a bisphosphine $\operatorname{Pd}(0)$ complex $\mathrm{PdL}_{2}$ (lit. $\delta 41.0 \mathrm{ppm}$ at $65^{\circ} \mathrm{C}$ in toluene- $\left.d_{8}\right)$, and an $\left[\left(\eta^{5}-\mathrm{Cp}\right) \operatorname{Pd}\left(\eta^{1}\right.\right.$-allyl $\left.) \mathrm{L}\right]$ species $\left(\left[\left(\eta^{5}-\mathrm{Cp}\right) \mathrm{Pd}\left(\eta^{1}-\mathrm{PhC}_{3} \mathrm{H}_{4}\right) \mathrm{L}\right]\right.$ lit. $\delta 61.7 \mathrm{ppm}$ at room temperature in toluene- $d_{8}$ ), respectively, as illustrated in Fig. 1. After stirring the mixture at $60{ }^{\circ} \mathrm{C}$ for $1 \mathrm{~h}$, the broadened weak peak at $\delta 62.0 \mathrm{ppm}$ corresponding to $\left[\left(\eta^{5}-\mathrm{Cp}\right) \operatorname{Pd}\left(\eta^{1}\right.\right.$-allyl $\left.) \mathrm{L}\right]$

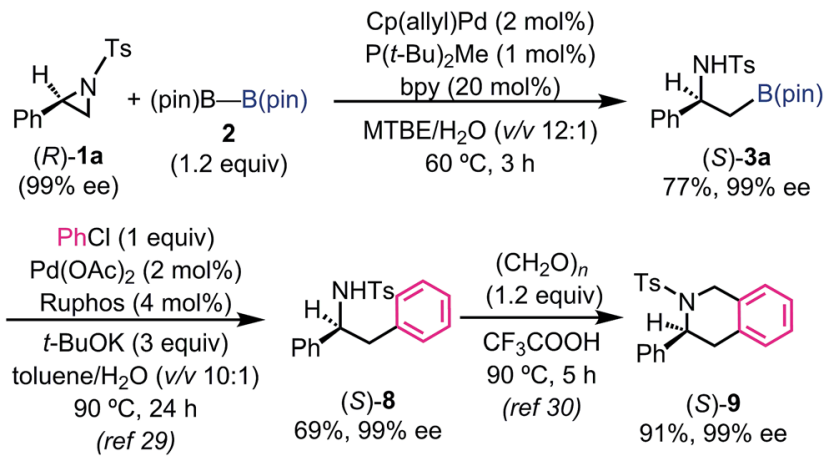

Scheme 1 Preparation of enantiopure $\beta$-aminoboronate and its synthetic application. 


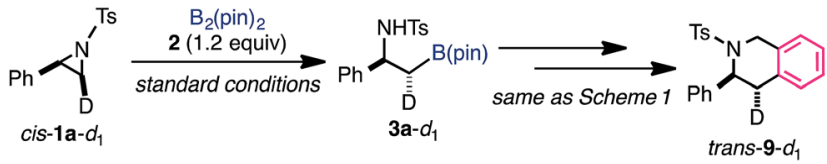

Scheme 2 Borylation of deuterated aziridine.

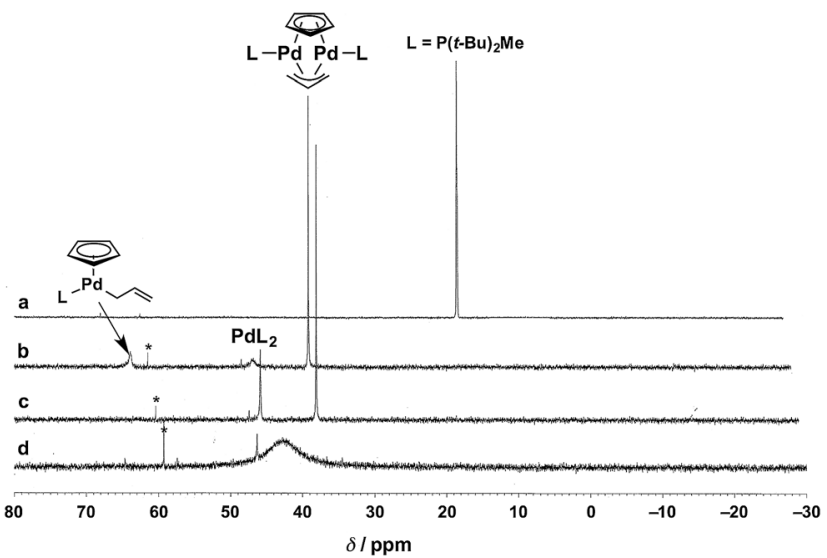

Fig. 1 Stacked ${ }^{31} P\left\{{ }^{1} H\right\} N M R$ spectra acquired at $60{ }^{\circ} \mathrm{C}$ in THF- $d_{8}$. (a) Free $L\left[L=P(t-B u)_{2} M e\right] ;(b, c)$ the reaction of $C p$ (allyl)Pd with 0.5 equiv. of $L$ ((b) upon mixing, (c) $1 \mathrm{~h}$ ); (d) the reaction of $C p$ (allyl)Pd with 1 equiv. of $L$ after $1 \mathrm{~h}$. The peaks with asterisks are attributed to phosphine oxide.

disappeared, and the intensity of the peak at $\delta 44.7 \mathrm{ppm}\left(\mathrm{PdL}_{2}\right)$ increased as well (the integration ratio of $\left[\operatorname{Pd}_{2} \mathrm{~L}_{2}(\mu-\mathrm{Cp})(\mu-\right.$ allyl)] $: \mathrm{PdL}_{2}=3: 2$, Fig. 1c). These peaks were not changed when bpy (10 equiv.) was added (Fig. S1b in the ESI $\dagger$ ). This result would indicate that bpy does not coordinate to these Pd species, which was also supported by our computational results (vide infra). Moreover, upon addition of another equivalent of $\mathrm{L}$ (i.e., $\mathrm{L}: \mathrm{Pd}=1$ ), the strongest sharp peak at $\delta 37.0 \mathrm{ppm}$ (dinuclear Pd complex) disappeared, and a broad peak around $\delta 42.6$ ppm appeared (Fig. 1d). Furthermore, addition of one more equivalent of $\mathrm{L}(\mathrm{L}: \mathrm{Pd}=2)$ gave a significantly broadened peak $(\delta \sim 30 \mathrm{ppm}$, Fig. S1a in the ESI $\dagger)$, indicating significant exchange among several $\mathrm{PdL}_{n}$ species. Our observations could indicate that $\mathrm{PdL}_{2}$ undergoes rapid exchange with $\mathrm{PdL}_{n}$ in THF$d_{8}$ when the $\mathrm{L}:$ Pd ratio is greater than 0.5. Therefore, the same would be the case with the real reaction system.

Based on the NMR experiments, $\left[\mathrm{Pd}_{2} \mathrm{~L}_{2}(\mu-\mathrm{Cp})(\mu\right.$-allyl)] or $\mathrm{PdL}_{2}$ would be the catalytically active Pd species (i.e., the starting point of the catalytic cycle). To determine which is the active species in the catalytic reaction, both complexes were generated separately as the sole components according to Baird's conditions (i.e., $1: 1$ and 2:1 mixtures of $\mathrm{L}$ and $\mathrm{Cp}($ allyl)Pd were mixed in toluene- $d_{8}$ and stirred at $77{ }^{\circ} \mathrm{C}$ for $1 \mathrm{~h}$ ), ${ }^{32}$ and the resulting Pd complexes were used as a catalyst in the borylation reaction in toluene (Schemes 3). As a result, while the dinuclear $\operatorname{Pd}(\mathrm{I})$ complex was found to be totally inert for the borylation reaction, the bisphosphine complex $\operatorname{Pd}(0) \mathrm{L}_{2}$ gave almost the same result as the real reaction system. Therefore, we conclude that $\operatorname{Pd}(0) \mathrm{L}_{2}$ would be the starting active species in the catalytic

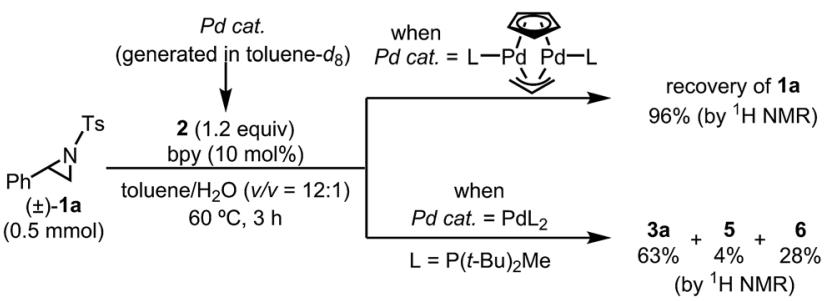

Scheme 3 Verification test of the catalytically active species.

cycle, and this conclusion was strongly supported by theoretical calculations (vide infra).

\section{Computational part}

Computational methods. Geometry optimizations were performed with the B3LYP-D3 ${ }^{33-36}$ functional as implemented in the Gaussian09 program. ${ }^{37}$ The polarizable continuum model (PCM) was used as the implicit solvent model with a dielectric constant $(\varepsilon)$ of $2.3714 .^{38}$ The SDD basis set and associated effective core potential were applied for $\mathrm{Pd}^{39,40}$ and $6-31 \mathrm{G}(\mathrm{d})$ basis sets were used for the other atoms (BS1). ${ }^{41-44}$ All stationary points, local minima (LMs) or transition states (TSs), were optimized without any constraint. Vibrational frequency calculations were performed to confirm the nature of the stationary points. Pseudo-IRC calculations were performed to confirm the connectivity between the TSs and LMs. The final potential energies of the optimized structures were calculated as singlepoint energies on the optimized structures, where a SDD basis set was used for Pd, and cc-pVTZ basis sets were used for the other atoms (BS2). ${ }^{45-47}$ In the results section, we report both the relative Gibbs free energy $(\Delta G)$ at $298.15 \mathrm{~K}$ and $1 \mathrm{~atm}$ and the relative electronic energy with the zero point energy correction $(\Delta E)$.

The aziridine ring opening step of the mechanism takes place via many different TSs, and therefore a proper sampling is very important. An automatic exploration of all important reaction pathways was accomplished using the multi-component artificial force induced reaction (MC-AFIR) method, as implemented in the global reaction route mapping (GRRM) strategy. ${ }^{48-50} \mathrm{An}$ artificial force parameter $(\gamma)$ of $300 \mathrm{~kJ} \mathrm{~mol}^{-1}$ was applied, and this is suitable for finding TSs within $300 \mathrm{~kJ} \mathrm{~mol}^{-1}$. The MC-AFIR calculations were terminated when no new AFIR LM was found for 10 consecutive AFIR paths $($ NFault $=10)$. In AFIR calculations, the energy and derivatives were obtained using the ONIOM(B3LYP-D3:PM6-D3) method. ${ }^{51-57}$ Partitioning of the molecular system is shown in Fig. 2a. A model catalyst was used for MC-AFIR calculations (Fig. 2). SDD basis sets and the associated effective core potentials were used for palladium, and 3-21G basis sets (BS3) were applied for the high-level region of ONIOM calculations. ${ }^{58-60}$ All AFIR paths were inspected and approximate TSs were identified. Then, the real phosphine ligand was introduced to all approximate TSs, and the TS structures were fully optimized (without artificial force) with B3LYP-D3/BS1 method. A Boltzmann distribution of the transition states was used to calculate the regioselectivity. 
Energy decomposition analysis (EDA) ${ }^{\mathbf{6 1 , 6 2}}$ was performed for the key TSs leading to the desired and the undesired products. B3LYP-D3/BS2 level and PCM were used for the EDA. In this analysis, a TS structure was divided into $\mathbf{A}$ (catalyst) and $\mathbf{B}$ (substrate) (Fig. 3). INT $_{\mathrm{AB}}$ is the interaction energy between $\mathbf{A}$ and $\mathbf{B}$ at their optimized TS structure. The deformation energy (DEF) is the energy of $\mathbf{A}$ and $\mathbf{B}$ at the optimized TS, relative to the optimized structures of isolated $\mathbf{A}$ and $\mathbf{B}$ (denoted as $\mathbf{A}_{0}$ and $\mathbf{B}_{0}$ ). The energy difference $(\Delta \Delta E)$ between the optimized transition states, $(\mathbf{A B})_{1}$ and $(\mathbf{A B})_{2}$, is the sum of the internal energy difference $\left(\Delta \mathrm{INT}_{\mathrm{AB}}\right)$ and the deformation energy difference $(\Delta \mathrm{DEF})$.

Thermodynamically stable complexes in solution. Our starting point was to explore thermodynamically stable complexes in solution. First, we checked the relative stability of $\mathrm{PdL}, \mathrm{PdL}_{2}, \mathrm{PdL}_{3}$, and $\mathrm{PdL}_{4}$ complexes $\left[\mathrm{L}=\mathrm{P}(t-\mathrm{Bu})_{2} \mathrm{Me}\right]$. Among them, the $\mathrm{PdL}_{2}$ complex (I) is the most stable complex, and this is in agreement with our NMR studies. The $\mathrm{PdL}_{3}$ and $\mathrm{PdL}$ complexes are 3.4 and $26.0 \mathrm{kcal} \mathrm{mol}^{-1}$ higher in energy, respectively. Despite several attempts, no $\mathrm{PdL}_{4}$ complex was found, as one of the four ligands (L) always dissociated due to steric repulsion. We used $\mathrm{PdL}_{2}(\mathbf{I})$ as a candidate to generate other possible complexes in solution. Moreover, the two vacant sites of the $\mathrm{PdL}_{2}$ complex, $\mathrm{A}$ and $\mathrm{B}$, can be filled by the potential ligands in solution, specifically $\mathrm{H}_{2} \mathrm{O}$, solvent (denoted as Sol), and additive (denoted as bpy). Table 3 summarizes the possible complexes and energies relative to the $\mathrm{PdL}_{2}$ complex (I).

Starting from the $\mathrm{PdL}_{2}$ complex (I), coordination of one $\mathrm{H}_{2} \mathrm{O}$, $\mathrm{L}$, and bpy on $\mathbf{I}$ gives rise to $\mathrm{PdL}_{2}\left(\mathrm{H}_{2} \mathrm{O}\right)\left(\mathbf{I w},-0.5 \mathrm{kcal} \mathrm{mol}^{-1}\right)$, $\mathrm{PdL}_{3}\left(3.4 \mathrm{kcal} \mathrm{mol}^{-1}\right)$, and $\mathrm{PdL}_{2}$ (bpy) (4.0 kcal $\left.\mathrm{mol}^{-1}\right)$ complexes, respectively. Among the three-coordinate complexes, Iw is the thermodynamically most stable complex, and is only $0.5 \mathrm{kcal} \mathrm{mol}^{-1}$ more stable than I. Therefore, both $\mathbf{I}$
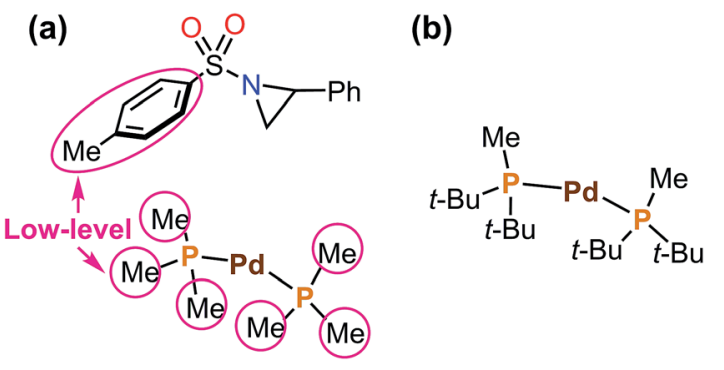

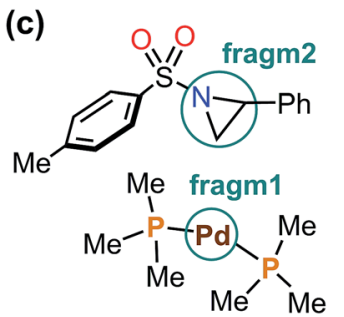

(I)

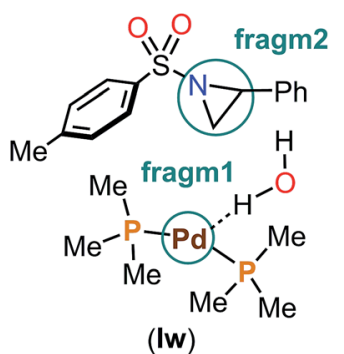

Fig. 2 (a) ONIOM partitioning of the model complex into high- and low-levels, (b) the real complex, (c) the artificial force $(\gamma=300 \mathrm{~kJ}$ $\mathrm{mol}^{-1}$ ) was applied between fragm1 (catalyst) and fragm2 (substrate) without or with an explicit water molecule.
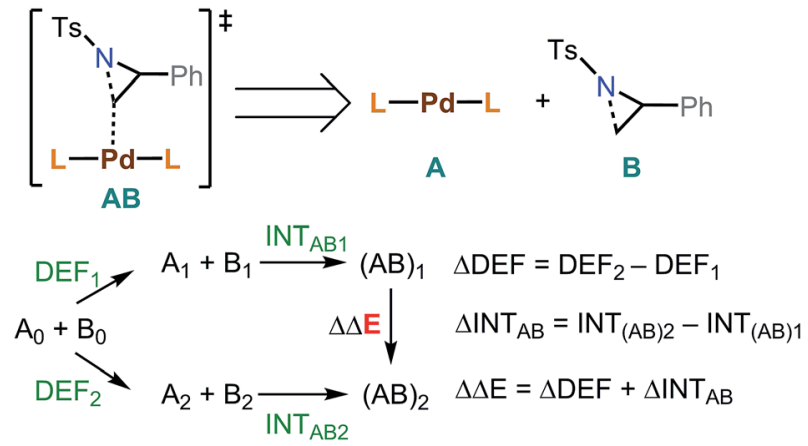

Fig. 3 EDA between two optimized transition states leading to the desired and undesired products.

and Iw can be formed in solution. In Iw, an $\mathrm{H}_{2} \mathrm{O}$ molecule coordinates to the metal with one of the two hydrogen atoms. It is important to note that the additive (bpy) can coordinate to the metal, and the resulting complex, $\mathrm{PdL}_{2}$ (bpy), is, however, 4.5 kcal mol ${ }^{-1}$ higher than the most stable complex, Iw. All fourcoordinate complexes found in the calculations, $\mathrm{PdL}_{2}(\mathrm{bpy})\left(\mathrm{H}_{2}\right.$ O) $\left(2.8 \mathrm{kcal} \mathrm{mol}^{-1}\right), \mathrm{PdL}_{2}\left(\mathrm{H}_{2} \mathrm{O}\right)_{2}\left(4.7 \mathrm{kcal} \mathrm{mol}^{-1}\right)$, and $\mathrm{PdL}_{3}\left(\mathrm{H}_{2} \mathrm{O}\right)$ $\left(7.9 \mathrm{kcal} \mathrm{mol}^{-1}\right)$ are relatively higher in energy. Coordination of solvent (Sol) is not possible due to steric repulsion between the bulky groups of the solvent molecules (MTBE) and I. We concluded that the thermodynamically most stable complexes in solution are Iw and I. The general rules that lead to the formation of the thermodynamically stable complexes in solution are: (1) coordination of two ligands on $\mathrm{PdL}_{2}$, which gives rise to four-coordinate complexes, is not favorable; (2) in terms of making three-coordinate complexes, the binding preference of the third ligand follows the order $\mathrm{H}_{2} \mathrm{O}>\mathrm{L}>$ bpy; (3) solvent MTBE would not coordinate to the $\mathrm{PdL}_{2}$ complex due to steric repulsion; (4) coordination of the additive (bpy) is not favorable. According to Table 3 , additive coordination on $\mathrm{PdL}_{2}$ is not favorable as the subsequent complex $\mathrm{PdL}_{2}$ (bpy) is $4.0 \mathrm{kcal}$ $\mathrm{mol}^{-1}$ higher than $\mathrm{PdL}_{2}$, while the $\mathrm{PdL}_{2}(\mathrm{bpy})_{2}$ complex is not stable. At the same time, it is important to note that aziridine binding on $\mathrm{PdL}_{2}$ is relatively easier (vide infra), and the corresponding adduct is only $2.6 \mathrm{kcal} \mathrm{mol}^{-1}$ higher than $\mathrm{PdL}_{2}$. Therefore, the additive would not coordinate to the $\mathrm{PdL}_{2}$ complex before the aziridine substrate binding. In our present mechanistic study, we do not consider the role of the additive in

Table 3 Possible complexes $\mathrm{Pd}(\mathrm{L})_{2}(\mathrm{~A})(\mathrm{B})\left[\mathrm{L}=\mathrm{P}(t-\mathrm{Bu})_{2} \mathrm{Me}\right.$, Sol $\left.=\mathrm{MTBE}\right]$ and their relative $\Delta G$ ( $\Delta E$ in parentheses) in $\mathrm{kcal} \mathrm{mol}^{-1 a}$

\begin{tabular}{llllll}
\hline & \multicolumn{5}{c}{$\mathrm{B}$} \\
\cline { 2 - 6 } A & Empty & $\mathrm{H}_{2} \mathrm{O}$ & bpy & $\mathrm{L}$ & Sol \\
\hline Empty & $0.0,(0.0)$ & $-0.5,(-8.2)$ & $4.0,(-7.4)$ & $3.4,(-10.9)$ & $\mathrm{X},($ Sol) \\
$\mathrm{H}_{2} \mathrm{O}$ & - & $4.7,(-14.0)$ & $2.8,(-17.9)$ & $7.9,(-15.1)$ & $\mathrm{X},($ Sol) \\
bpy & - & - & $\mathrm{X},(\mathrm{bpy})$ & $\mathrm{X},(\mathrm{L})$ & $\mathrm{X},($ Sol $)$ \\
L & - & - & - & $\mathrm{X},(\mathrm{L})$ & $\mathrm{X},($ Sol) \\
Sol & - & - & - & - & $\mathrm{X},($ Sol)
\end{tabular}

${ }^{a}$ The symbol " $\mathrm{X}$ " indicates that the ligand in parentheses dissociates upon structure optimization. 
the mechanism because the reaction works even in the absence of additive (Table 1, entry 4 ).

Aziridine ring-opening step. Our next task was the exploration of the aziridine ring-opening step. For this purpose, we used the most stable $\mathbf{I}$ and Iw complexes as the active intermediates for the reaction, and 2-phenyl- $N$-tosyl-aziridine (1) was used as the substrate. Therefore, two independent MC-AFIR calculations, with and without an explicit water molecule, were performed as shown in Fig. 2c. The fully optimized TS structures, 73 TSs from Iw and 33 TSs from I, were categorized into 15 groups: TSI-II $\mathbf{I}_{\mathbf{A}}$ through TSI-II $\mathbf{J}_{\mathbf{J}}$ from Iw, and TSI-III through TSI$\mathbf{I I}_{\mathbf{O}}$ from I, based on structural similarities (Fig. 4). The lowest energy TS of each group, their relative energies, and their existence probability are depicted in Table 4 (see Table S14 in the ESI $\dagger$ for a full description of all the TSs).

Among the calculated TSs (Table 4), TS1-t-lw (12.6 kcal $\mathrm{mol}^{-1}$ ) which belongs to the TSI-II $\mathbf{K}_{\mathbf{K}}$ group is the lowest energy TS of this step. In this TS, the aziridine ring opening takes place at the less hindered carbon in an $\mathrm{S}_{\mathrm{N}} 2$ fashion, leading to the desired product forming. The same product can be obtained through TS2-t-lw (12.9 kcal mol $\left.{ }^{-1}\right)$, TS4-t-l $\left(13.3 \mathrm{kcal} \mathrm{mol}^{-1}\right)$, TS5-t-lw (13.4 $\left.\mathrm{kcal} \mathrm{mol}^{-1}\right)$, TS6-t-1 (13.5 kcal mol $\left.{ }^{-1}\right)$, TS7-t-1 (13.6 kcal mol $\left.{ }^{-1}\right)$, TS8-t-l $\left(13.7 \mathrm{kcal} \mathrm{mol}^{-1}\right)$, and TS9-t-lw $(13.9 \mathrm{kcal}$ $\left.\mathrm{mol}^{-1}\right)$. On the other hand, at TS3-b-lw (13.2 $\mathrm{kcal} \mathrm{mol}^{-1}$ ) of the group TSI-II $\mathbf{L}_{\mathbf{L}}$, aziridine ring opening occurs at the hindered carbon (the 2-position), and this is the lowest TS leading to the undesired product. Based on a Boltzmann distribution over the calculated TSs, the regioselectivity is calculated to be $89: 11$, which is qualitatively in agreement with the experimental results $(99: 1)$.

In the calculated TSs for TSI-II $\mathbf{E}_{\mathbf{E}}\left(31.5 \mathrm{kcal} \mathrm{mol}^{-1}\right)$, TSI-II $\mathbf{F}$ (30.9 $\left.\mathrm{kcal} \mathrm{mol}^{-1}\right)$, and TSI-II $\mathbf{M}\left(24.7 \mathrm{kcal} \mathrm{mol}^{-1}\right)$, aziridine ring opening occurs at the less hindered carbon (Fig. 4). However,

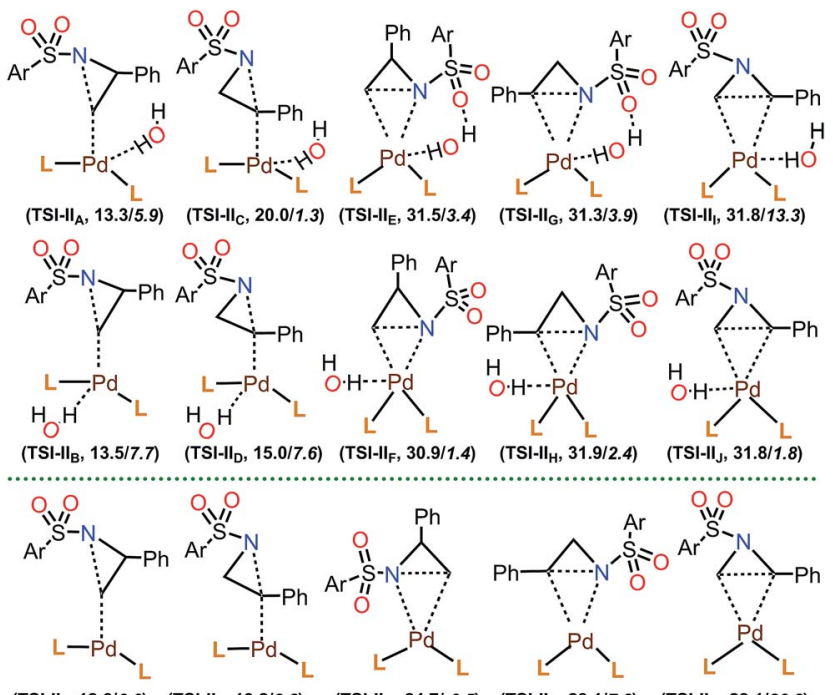

$\left(T S I-I_{K}, 12.6 / 6.0\right) \quad\left(T S I-I_{L}, 13.2 / 9.2\right) \quad\left(T S I-I_{M}, 24.71-0.5\right) \quad\left(T S I-I_{N}, 28.1 / 7.3\right) \quad\left(T S I-I_{O}, 28.1 / 20.2\right)$

Fig. 4 Groups of transition states for the aziridine ring opening, starting from Iw $\left(\mathrm{TSI}-\mathrm{II}_{\mathrm{A}}\right.$ through TSI- $\mathrm{II}_{\mathrm{J}}$ ) and I (TSI-II $\mathrm{K}_{\mathrm{K}}$ through TSI-II $)$, and energies of the lowest energy TS of each group relative to the $\mathrm{PdL}_{2}\left(\mathrm{H}_{2} \mathrm{O}\right)(\mathrm{Iw})$ complex $\left(\mathrm{Ar}=p\right.$-tolyl; $\left.\mathrm{L}=\mathrm{P}(t-\mathrm{Bu})_{2} \mathrm{Me}\right) . \Delta G$ values are in plain text, and $\Delta E$ values are in italics. these TSs are relatively higher in energy due to the fact that the $N$-p-toluenesulfonyl and 2-phenyl substituents of the substrate are much closer to the bulky groups of Iw or I. Similarly, TSs in the group of TSI-II $_{\mathbf{G}}\left(31.3 \mathrm{kcal} \mathrm{mol}^{-1}\right)$, TSI-II $\mathbf{H}\left(31.9 \mathrm{kcal} \mathrm{mol}^{-1}\right)$, and TSI-II $\mathbf{I}_{\mathbf{N}}\left(28.1 \mathrm{kcal} \mathrm{mol}^{-1}\right)$ show high energy barriers, where aziridine ring opening occurs at the hindered carbon. TSs in the group of TSI-III $\left(31.8 \mathrm{kcal} \mathrm{mol}^{-1}\right)$, TSI-II $\mathbf{J}\left(31.8 \mathrm{kcal} \mathrm{mol}^{-1}\right)$, and TSI-II $_{\mathbf{O}}\left(28.1 \mathrm{kcal} \mathrm{mol}^{-1}\right)$ represent the aziridine ring opening through the carbon-carbon bond, which is, however, not possible due to very large reaction barriers. Furthermore, we checked the effect of $\mathrm{H}_{2} \mathrm{O}$ molecules on aziridine ring opening. Starting from the lowest energy TS for this step (TS1-t-lw, 12.6 $\mathrm{kcal} \mathrm{mol}^{-1}$ ), up to four $\mathrm{H}_{2} \mathrm{O}$ molecules were introduced, and the corresponding TSs were calculated. The calculated $\Delta G$ of TS1-tlw with one $\mathrm{H}_{2} \mathrm{O}$ molecule (TS1-t-lw-w, $16.1 \mathrm{kcal} \mathrm{mol}^{-1}$ ), two $\mathrm{H}_{2} \mathrm{O}$ molecules (TS1-t-lw-w $\mathbf{w}_{2}, 14.3 \mathrm{kcal} \mathrm{mol}^{-1}$ ), three $\mathrm{H}_{2} \mathrm{O}$ molecules (TS1-t-lw-w 3 , $15.6 \mathrm{kcal} \mathrm{mol}^{-1}$ ), and four $\mathrm{H}_{2} \mathrm{O}$ molecules (TS1-t-lw-w 4 , $16.4 \mathrm{kcal} \mathrm{mol}^{-1}$ ) suggested that explicit $\mathrm{H}_{2} \mathrm{O}$ molecules in the system would not stabilize the TS1-t-lw.

TS1-t-lw is a major contributor to the aziridine ring opening at the less hindered carbon, while TS3-b-lw is the lowest TS for aziridine ring opening at the hindered carbon (Fig. 5). The calculated Gibbs free energy difference between TS1-t-lw and TS3-b-lw is $0.6 \mathrm{kcal} \mathrm{mol}^{-1}$, while the potential energy difference is $3.2 \mathrm{kcal} \mathrm{mol}^{-1}$. When we do not consider the zero point energy corrections, the potential energy difference is $3.5 \mathrm{kcal}$ $\mathrm{mol}^{-1}$, and we have used this value for the EDA. According to the EDA (Table 5), the origin of this difference comes from $\Delta \mathrm{INT}_{\mathrm{AB}}\left(3.9 \mathrm{kcal} \mathrm{mol}^{-1}\right)$, indicating better interactions at TS1-tlw. This is due to the fact that the aziridine substrate can approach closer to the metal in TS1-t-lw $(\mathrm{Pd}-\mathrm{C}=2.47 \AA)(v s$. Pd$\mathrm{C}=2.61 \AA$ at TS3-b-lw) (Fig. 5) than in TS3-b-lw due to the lower steric repulsion.

The free energy profile for the early stages of the mechanism is shown in Fig. 6. The reaction starts from the thermodynamically most stable complex, Iw. Therefore, we report energies relative to Iw. Then, aziridine coordination on I leads to a complex II $\left(2.6 \mathrm{kcal} \mathrm{mol}^{-1}\right)$, and the subsequent aziridine ring opening occurs through TS1-t-lw (TSII-III, $12.6 \mathrm{kcal} \mathrm{mol}^{-1}$ ). Aziridine ring opening is also possible from Iw (not shown in Fig. 6) with an overall barrier of $13.3 \mathrm{kcal} \mathrm{mol}^{-1}$ (TS4-t-lw), which is, however, $0.7 \mathrm{kcal} \mathrm{mol}^{-1}$ higher than TS1-t-lw. Beyond TS1-t-lw, an intermediate, III ( $\left.8.4 \mathrm{kcal} \mathrm{mol}^{-1}\right)$ is formed.

Proton transfer to anionic amine. The next step of the mechanism would be a proton transfer from $\mathrm{H}_{2} \mathrm{O}$ molecules in solution to the anionic nitrogen atom in the water-coordinated intermediate III. This proton transfer process takes place smoothly from $\mathrm{IIw}_{3}\left(0.3 \mathrm{kcal} \mathrm{mol}^{-1}\right)$, which is $8.1 \mathrm{kcal} \mathrm{mol}^{-1}$ more stable than III. Furthermore, three $\mathrm{H}_{2} \mathrm{O}$ molecules make a hydrogen bonding network starting from the anionic amine that is connected to the metal through a water oxygen coordination. The TS for this proton transfer process is $12.0 \mathrm{kcal}$ $\mathrm{mol}^{-1}$ (TSIII-IVw $\mathbf{I}_{3}$ ). Proton transfer is also possible from the analogous intermediate with four $\mathrm{H}_{2} \mathrm{O}$ molecules, $\mathbf{I I w}_{\mathbf{4}}$ (11.3 $\mathrm{kcal} \mathrm{mol}^{-1}$ ), and the subsequent transition state is, however, 1.3 kcal mol ${ }^{-1}$ higher than TSIII-IVw $\mathbf{w}_{3}$ (not shown in Fig. 6). We were unable to locate TSs starting from the analogous 
Table 4 Low energy TSs for the aziridine ring opening starting from I and $\mathrm{Iw}^{a}$

\begin{tabular}{lllll}
\hline TS & Group/regioselectivity & $\Delta \Delta G$ & $\Delta G(\Delta E)$ & Existence probability (\%) \\
\hline TS1-t-lw & K/terminal & 0.0 & $12.6(6.0)$ & 27.6 \\
TS2-t-lw & K/terminal & 0.3 & $12.9(5.4)$ & 17.9 \\
TS3-b-lw & L/benzylic & 0.6 & $13.2(9.2)$ & 10.0 \\
TS4-t-l & A/terminal & 0.7 & $13.3(5.9)$ & 9.6 \\
TS5-t-lw & K/terminal & 0.8 & $13.4(6.9)$ & 7.1 \\
TS6-t-l & B/terminal & 0.9 & $13.5(7.7)$ & 6.1 \\
TS7-t-l & B/terminal & 1.0 & $13.6(7.7)$ & 4.8 \\
TS8-t-l & A/terminal & 1.1 & $13.7(6.8)$ & 4.6 \\
TS9-t-lw & K/terminal & 1.3 & $13.9(7.6)$ & 2.9 \\
TS10-t-lw & K/terminal & 2.3 & $14.9(7.6)$ & 0.6 \\
TS11-b-l & D/benzylic & 2.4 & $15.0(7.6)$ & 0.5 \\
TS12-t-lw & K/terminal & 2.6 & $15.2(-1.2)$ & 0.4 \\
TS13-t-lw & K/terminal & 2.6 & $15.2(8.3)$ & 0.3 \\
TS14-t-lw & K/terminal & 2.7 & $15.3(7.5)$ & 0.3 \\
TS15-t-lw & K/terminal & 3.3 & $15.9(9.0)$ & 0.1 \\
TS16-t-lw & K/terminal & 3.5 & $16.1(8.3)$ & \\
TS17-t-lw & K/terminal & 3.6 & $16.2(7.9)$ & 0.1 \\
TS18-t-l & B/terminal & 3.7 & $16.3(9.2)$ & \\
TS19-t-l & A/terminal & 3.7 & $16.3(-0.8)$ & 0.1
\end{tabular}

${ }^{a} \Delta G$ and $\Delta E$ values are indicated in $\mathrm{kcal} \mathrm{mol}^{-1}$, relative to Iw. " $\mathrm{t}$ " and "b" indicate the terminal (3-position) and benzylic carbons (2-position), respectively.
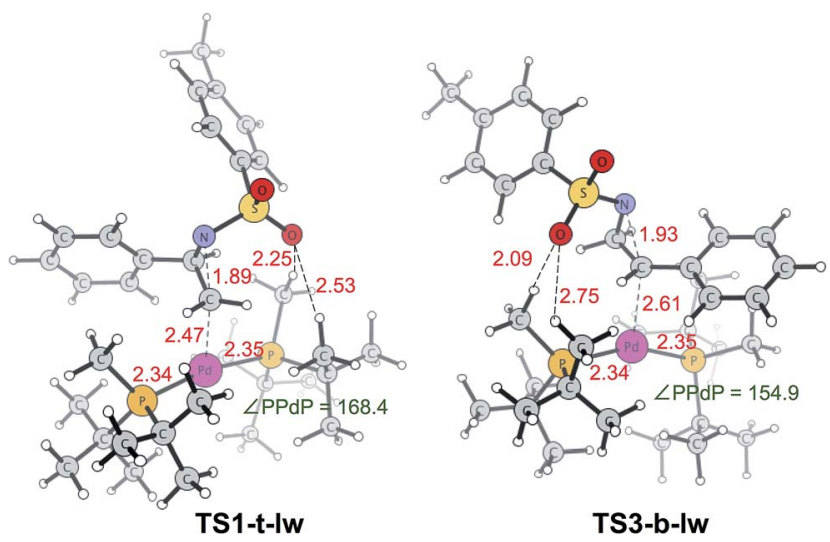

Fig. 5 Lowest energy TSs leading to the desired product (TS1-t-lw) and undesired product (TS3-b-lw). Bond lengths (red) are in $\AA$ and bond angles (green) are in degrees.

Table 5 EDA for the potential energy difference $\left(\mathrm{kcal} \mathrm{mol}^{-1}\right)$ between the key transition states, TS1-t-lw and TS3-b-lw

\begin{tabular}{llll}
\hline TS & $\mathrm{DEF}\left(\mathrm{DEF}_{\mathrm{A}}, \mathrm{DEF}_{\mathrm{B}}\right)$ & $\mathrm{INT}_{\mathrm{AB}}$ & $\Delta E$ \\
\hline TS1-t-lw & $23.2(1.2,22.0)$ & -26.5 & -3.3 \\
TS3-b-lw & $22.8(2.7,20.1)$ & -22.6 & 0.2 \\
& $\Delta \mathbf{D E F}$ & $\Delta \mathrm{INT}_{\mathrm{AB}}$ & $\mathbf{\Delta} \boldsymbol{\Delta E}$ \\
& $-0.4(-1.5,1.1)$ & 3.9 & 3.5
\end{tabular}

intermediates with two $\mathrm{H}_{2} \mathrm{O}$ molecules ( $\mathbf{I I I}_{2}, 1.1 \mathrm{kcal} \mathrm{mol}^{-1}$ ) and one $\mathrm{H}_{2} \mathrm{O}$ molecule (IIIw, $2.3 \mathrm{kcal} \mathrm{mol}^{-1}$ ), where the potential energy surface for the proton transfer processes was found to be repulsive (Fig. $\mathrm{S} 2$ and $\mathrm{S} 3 \dagger$ ). In $\mathbf{I I I w}_{3}$, three water molecules form a complete head-to-tail chain between the anionic amines and Pd centres. As a result, the synchronous three proton transfer via $\mathbf{T S I I I}-\mathbf{I V w}_{\mathbf{3}}$ takes place and gives a protonated $\mathrm{N}$, two $\mathrm{H}_{2} \mathrm{O}$ molecules, and a hydroxyl group bound to the metal center. Based on our analysis, we conclude that three $\mathrm{H}_{2} \mathrm{O}$ molecules are required for the proton transfer process, leading to an intermediate $\mathbf{I V w}_{3}\left(2.0 \mathrm{kcal} \mathrm{\textrm {mol } ^ { - 1 }}\right)$. Once the proton is transferred, the chain of water molecules is no longer required, and the corresponding intermediate without $\mathrm{H}_{2} \mathrm{O}$, IV, is $2.7 \mathrm{kcal}$ $\mathrm{mol}^{-1}$ more stable than $\mathbf{I V w}_{3}$.

B-B bond coordination and cleavage. Now, the B(pin)-B(pin) species binds to IV and the subsequent intermediate $\mathbf{V}(0.5 \mathrm{kcal}$ $\mathrm{mol}^{-1}$ ) is formed. Starting from $\mathbf{V}$, inner-sphere B-B bond cleavage does not take place due to steric repulsion between the bulky alkyl groups in $\mathrm{L}$ and $\mathrm{B}$ (pin)-B(pin). One of the two phosphine ligands of the catalyst must dissociate, and the resulting intermediate, VI, is only $1.8 \mathrm{kcal} \mathrm{mol}^{-1}$ higher than $\mathbf{V}$. Then, B-B bond cleavage takes place in an inner sphere fashion with a barrier of $10.8 \mathrm{kcal} \mathrm{mol}^{-1}$ (TSVI-VII), giving rise to VII $\left(-2.1 \mathrm{kcal} \mathrm{mol}^{-1}\right)$. We have checked the possibility of ligand exchange between the (pin)B-OH and a stronger phosphine ligand L on intermediate VII, and the resulting complex, VIII, is $24.5 \mathrm{kcal} \mathrm{mol}^{-1}$ more stable than VII.

cis-trans isomerization and reductive elimination. The energy profiles for the final stages of the reaction are shown in Fig. 7. In both the intermediates VII and VIII, B(pin) is trans to the alkyl group derived from the aziridine substrate, and therefore cis/trans isomerization must take place before the reductive elimination. The cis isomer $\mathbf{V I I I}^{\prime}$ is $2.5 \mathrm{kcal} \mathrm{mol}^{-1}$ more stable than the trans isomer VIII. This step may occur through ligand dissociation processes. Since we expect this isomerization to be a low energy process, we did not study this in depth. The subsequent reductive elimination from $\mathbf{V I I I}^{\prime}$ occurs through a barrier of $0.1 \mathrm{kcal} \mathrm{mol}^{-1}$ (TSVIII'-IX). In the resulting intermediate $\mathbf{I X}$, the product $(\mathbf{P})$ is still at the metal 


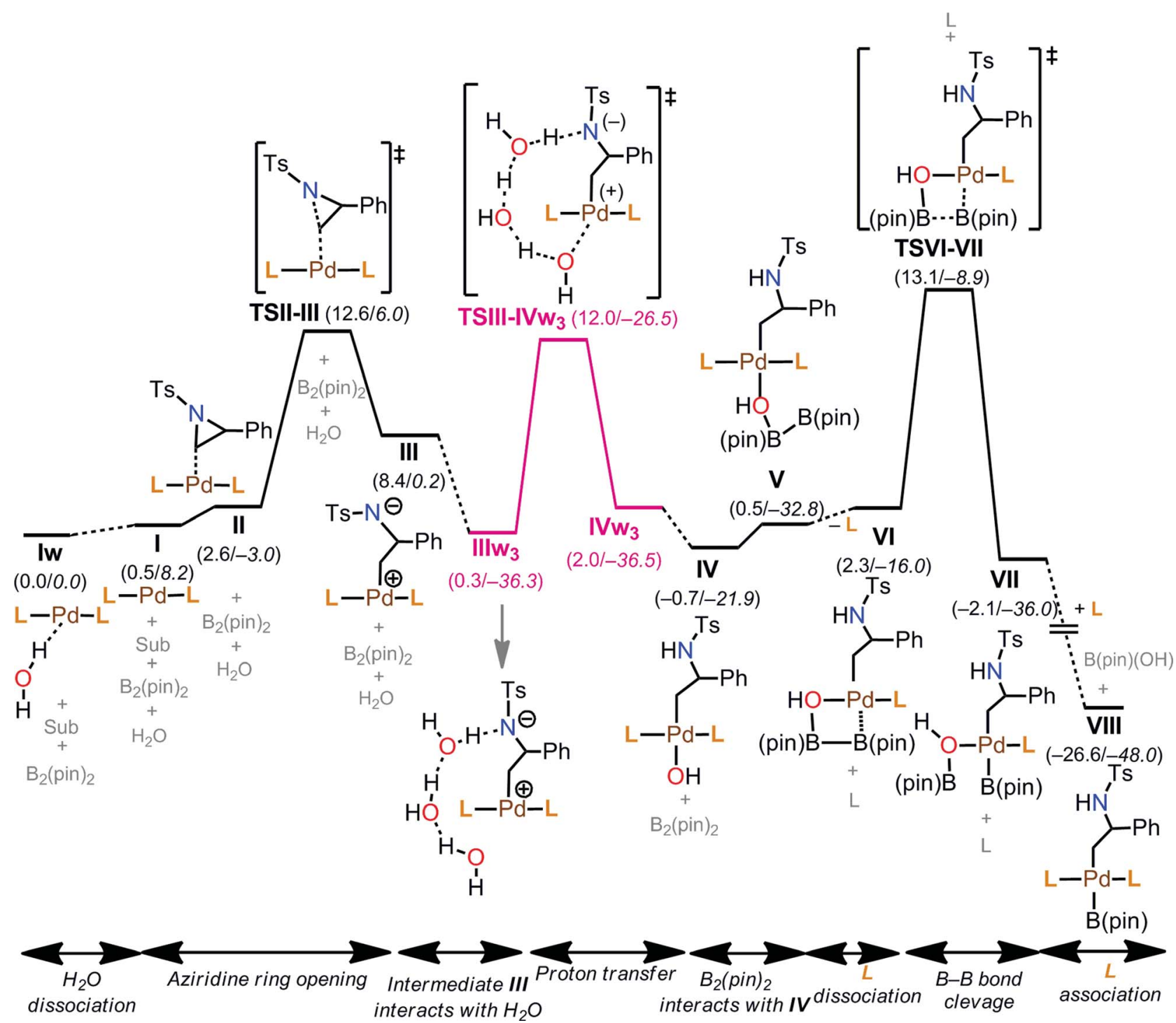

Fig. 6 Free energy profile for the reaction mechanism (aziridine ring opening, proton transfer, and B-B bond cleavage processes). Energies are indicated in $\mathrm{kcal} \mathrm{mol}^{-1} . \Delta G$ values are in plain text, and $\Delta E$ values are in italics.

coordination sphere, and $\mathbf{P}$ can be removed easily to recover the active form of the catalyst, $\mathrm{PdL}_{2}$ (I), for the next catalytic cycle. Similarly, the formation of the cis isomer of VII, the less stable intermediate VII' $\left(-19.4 \mathrm{kcal} \mathrm{mol}^{-1}\right)$, and the subsequent reductive elimination can occur easily with a barrier of $5.7 \mathrm{kcal} \mathrm{mol}^{-1}$ (TSVII'-X). Then, a phosphine ligand (L) can coordinate to the resulting intermediate $\mathbf{X}$, which ultimately yields the product, $\mathbf{P}$.

\section{Side product formation}

Under the optimized reaction conditions, imine $\mathbf{6}$ is formed as a side product (Table 1). We have explored the mechanism for the side reaction as shown in Fig. S4 in the ESI. $\dagger$

\section{Catalytic cycle}

Putting together the present results from the experimental and theoretical studies, the proposed catalytic cycle for the borylation is shown in Fig. 8 (black cycle). $\operatorname{Pd}(0) \mathrm{L}_{2}$ is generated through the sequential reduction of $\mathrm{Cp}\left(\right.$ allyl)Pd. Then, $\operatorname{Pd}(0) \mathrm{L}_{2}$ attacks the less hindered carbon of the aziridine in an $\mathrm{S}_{\mathrm{N}} 2$ fashion (a) to give a stereo-inverted oxidative adduct. A hydrogen bonded chain of $\mathrm{H}_{2} \mathrm{O}$ molecules plays two roles in the following steps: (i) as a proton source to quench $\mathrm{TsN}^{-}$(b) and (ii) as an internal base to form the $[\mathrm{Pd}(\mathrm{OH})]$ species. This intermediate activates the $\mathrm{B}-\mathrm{B}$ bond of $\mathrm{B}_{2}(\mathrm{pin})_{2}(\mathrm{c})$. The dissociation of a phosphine ligand $(\mathrm{d})$ facilitates the transmetalation (e). The free phosphine ligand participates in the catalytic cycle again to form the (alkyl) $\mathrm{PdL}_{2} \mathrm{~B}$ (pin) complex (f). The trans-cis isomerization $(\mathrm{g})$ followed by reductive elimination $(\mathrm{h})$ leads to the $\mathrm{C}-\mathrm{B}$ cross-coupled product and the completion of the catalytic cycle. A side reaction may occur after the oxidation addition (brown cycle): the oxidative adduct of aziridine undergoes hydrogen transfer (i) followed by reductive elimination (j) to produce an imine byproduct. Our computational study suggests that the aziridine ring-opening step for substrate 1a has barriers of $12.6 \mathrm{kcal} \mathrm{mol}^{-1}$ (terminal position) and 


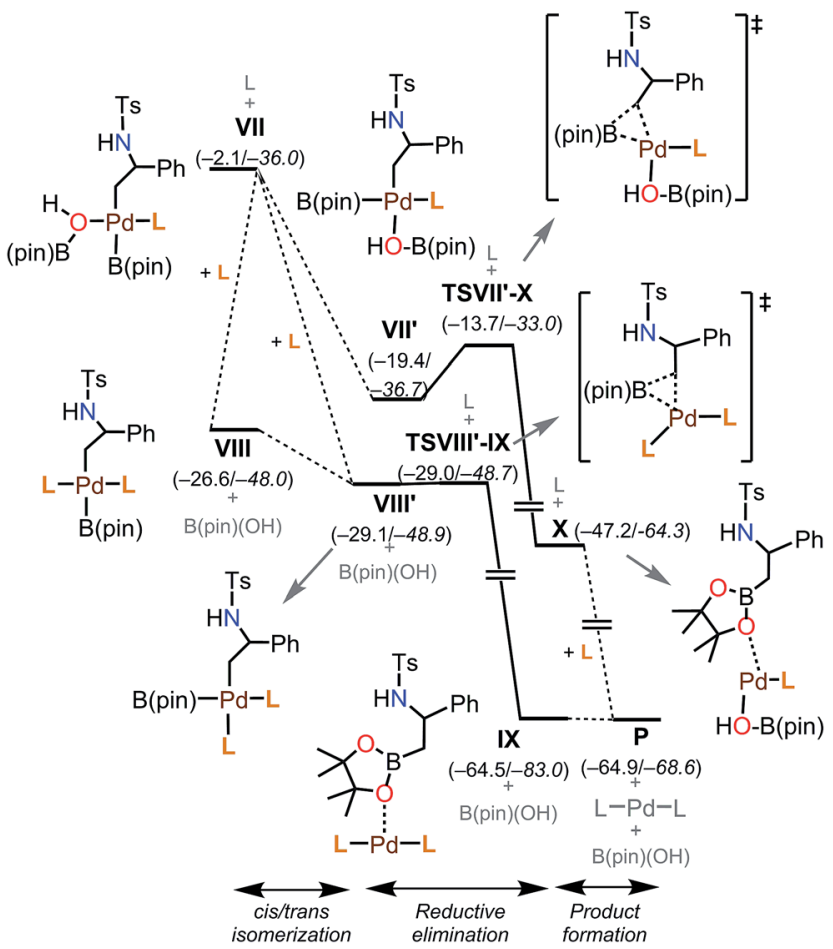

Fig. 7 Free energy profile for the later steps of the mechanism. Energies are indicated in $\mathrm{kcal} \mathrm{mol}^{-1}, \Delta G$ values are in plain text, and $\Delta E$ values are in italics.

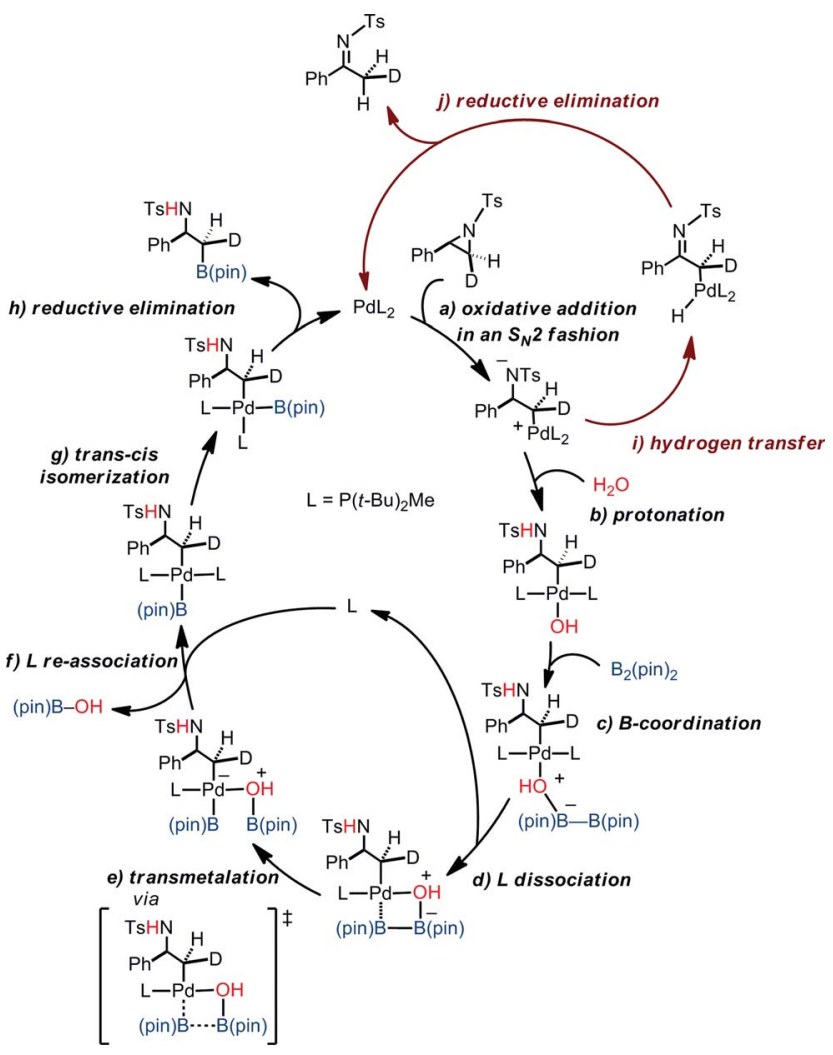

Fig. 8 A proposed catalytic cycle of the borylation.
$13.2 \mathrm{kcal} \mathrm{mol}^{-1}$ (benzylic position) (Table 4). For an alkyl aziridine, in particular 11, the aziridine ring-opening step showed barriers of $15.4 \mathrm{kcal} \mathrm{mol}^{-1}$ (2-position) and $16.3 \mathrm{kcal} \mathrm{mol}^{-1}$ (3position). In the absence of the aryl group, the aziridine ring opening of 11 is $2.8 \mathrm{kcal} \mathrm{mol}^{-1}$ higher than $\mathbf{1}$, where the reaction is difficult with 1l. This is qualitatively in agreement with our experimental results, where the reaction does not proceed with 11.

\section{Conclusions}

In conclusion, we have developed a Pd-catalyzed regioselective borylative ring opening reaction of 2 -arylaziridines to give $\beta$ aminoalkylboronates that are otherwise difficult to synthesize using existing methodologies. Importantly, the regioselectivity of the ring opening is controlled by the interactions between the catalyst and the substrate. The $\mathrm{S}_{\mathrm{N}} 2$ nature of the oxidative addition of aziridine was verified using deuterated aziridine and computational studies. Furthermore, the borylative reaction is applicable under neutral conditions that allow for high functional compatibility. The mechanism of the full catalytic cycle was proposed using DFT and MC-AFIR methods. The aziridine ring opening is initiated by the active species $\mathrm{PdL}_{2}$. TSs were systematically determined for the selectivity-determining aziridine ring opening step, and the calculations reasonably reproduced the experimental regioselectivity. The next step of the mechanism is a proton transfer that is facilitated by $\mathrm{H}_{2} \mathrm{O}$ hydrogen bond chain. The resulting Pd-hydroxo species activates the transmetalation step, where inner sphere boronboron bond cleavage occurs, and leads to the final reductive elimination step. These experimental and theoretical findings open up an avenue to the further development of transition metal-catalyzed ring-opening $\mathrm{C}-\mathrm{E}$ bond forming cross couplings of aziridines.

\section{Acknowledgements}

This work was partly supported by a Scientific Research on Innovative Area (JSPS KAKENHI Grant Number JP16H01023 in Precisely Designed Catalysis with Customized Scaffolding, to YT) from MEXT, Japan, and by a Research Grant for the Toray Award in Synthetic Organic Chemistry from the Society of Synthetic Organic Chemistry, Japan (to YT). One of the authors (YT) would like to acknowledge all the warm support from the Frontier Research Base for Global Young Researchers, Osaka University, on the Program of MEXT, Japan. WMCS and KM are grateful to Prof. Satoshi Maeda of Hokkaido University for the developmental version of the GRRM code. WMCS acknowledges JSPS for a Foreign Postdoctoral Fellowship (P14334). This work was in part supported by Grants-in-Aid for Scientific Research (KAKENHI 15H00938 and 15H02158) to KM at Kyoto University. The computer resources at the Institute for Information Management and Communication (IIMC) at Kyoto University and Research Center of Computational Science (RCCS) at the Institute for Molecular Science are also acknowledged. 


\section{Notes and references}

1 Aziridines and Epoxides in Organic Synthesis, ed. A. K. Yudin, Wiley-VCH, Weinheim, 2006.

2 For reviews on ring opening of aziridines, see: (a) D. Tanner, Angew. Chem., Int. Ed. Engl., 1994, 33, 599-619; (b) X. E. Hu, Tetrahedron, 2004, 60, 2701-2743; (c) P. Lu, Tetrahedron, 2010, 66, 2549-2560; (d) S. Stanković, M. D'hooghe, S. Catak, H. Eum, M. Waroquier, V. V. Speybroeck, N. De Kimpe and H. J. Ha, Chem. Soc. Rev., 2011, 41, 643-665.

3 For a review on the preparation and reactivities of azametallacyclobutanes, see: A. Dauth and J. A. Love, Dalton Trans., 2012, 41, 7782-7791.

4 B. L. Lin, C. R. Clough and G. L. Hillhouse, J. Am. Chem. Soc., 2002, 124, 2890-2891.

5 J. E. Ney and J. P. Wolfe, J. Am. Chem. Soc., 2006, 128, 1541515422.

6 (a) H. Alper, F. Urso and D. J. H. Smith, J. Am. Chem. Soc., 1983, 105, 6737-6738; (b) S. Calet, F. Urso and H. Alper, J. Am. Chem. Soc., 1989, 111, 931-934; (c) M. E. Piotti and H. Alper, J. Am. Chem. Soc., 1996, 118, 111-116; (d) P. Davoli, I. Moretti, F. Prati and H. Alper, J. Org. Chem., 1999, 64, 518-521.

7 For a review on the transition metal-catalyzed transformations of small ring compounds including aziridines, see: C.-Y. Huang and A. G. Doyle, Chem. Rev., 2014, 114, 8153-8198.

8 A wide variety of ring expansions of vinylaziridines via $\pi$-allylmetal species and ring-opening $\mathrm{S}_{\mathrm{N}} 2^{\prime}$ substitutions have been developed. For reviews, see: $(a)$ E. A. Ilardi and J. T. Njardarson, J. Org. Chem., 2013, 78, 9533-9540; (b) H. Ohno, Chem. Rev., 2014, 114, 7784-7814.

9 Wolfe and coworkers reported a $\mathrm{Pd} / \mathrm{PR}_{3}$-catalyzed isomerization of aziridines to ketimines via a tandem process consisting of oxidative addition/ $\beta$-hydride elimination/tautomerization, see: J. P. Wolfe and J. E. Ney, Org. Lett., 2003, 5, 4607-4610.

10 (a) C.-Y. Huang and A. G. Doyle, J. Am. Chem. Soc., 2012, 134, 9541-9544; (b) D. K. Nielsen, C.-Y. Huang and A. G. Doyle, J. Am. Chem. Soc., 2013, 135, 13605-13609; (c) C.-Y. Huang and A. G. Doyle, J. Am. Chem. Soc., 2015, 137, 5638-5641; (d) K. L. Jensen, E. A. Standley and T. F. Jamison, J. Am. Chem. Soc., 2014, 136, 11145-11152.

11 (a) M. L. Duda and F. E. Michael, J. Am. Chem. Soc., 2013, 135, 18347-18349; (b) Y. Takeda, Y. Ikeda, A. Kuroda, S. Tanaka and S. Minakata, J. Am. Chem. Soc., 2014, 136, 8544-8547.

12 The Pineschi group reported a $\mathrm{Ni}(0)$-catalyzed borylative ring opening of vinylaziridines that proceeds in a formal $\mathrm{S}_{\mathrm{N}} 2^{\prime}$ fashion. Apparently, this reaction proceeds through an oxidative addition of vinylaziridines to $\mathrm{Ni}(0)$ to generate a $\pi$-allyl Ni(II) species. However, little is described about its mechanism: S. Crotti, F. Bertolini, F. Macchia and M. Pineschi, Org. Lett., 2009, 11, 3762-3765.

13 (a) Boronic Acids: Preparation and Applications in Organic Synthesis, Medicine and Materials, ed. D. G. Hall, WileyVCH, Weinheim, 2nd edn, 2011; (b) C. M. Crudden,
B. W. Glasspoole and C. J. Lata, Chem. Commun., 2009, 6704-6716; (c) H. K. Scott and V. K. Aggarwal, Chem.-Eur. J., 2011, 17, 13124-13132.

14 S. Sebelius, V. J. Olsson and K. J. Szabó, J. Am. Chem. Soc., 2005, 127, 10478-10479.

15 As a relevant transformation, a metal-free borylative ring opening of vinyl epoxides and aziridines has been reported: X. Sanz, G. M. Lee, C. Pubill-Ulldemolins, A. Bornet, H. Gulyás, S. A. Westcott, C. Bo and E. Fernández, Org. Biomol. Chem., 2013, 11, 7004-7010.

16 For selected examples of synthetic methods of $\beta$ aminoboronates, see: (a) D. N. Butler and A. H. Soloway, J. Am. Chem. Soc., 1964, 86, 2961; (b) D. H. Kinder and M. M. Ames, J. Org. Chem., 1987, 52, 2452-2454; (c) C. Morin, Tetrahedron, 1994, 50, 12521-12569; (d) G. A. Molander and F. Vargas, Org. Lett., 2007, 9, 203-206; (e) N. Matsuda, K. Hirano, T. Satoh and M. Miura, J. Am. Chem. Soc., 2013, 135, 4934-4937; (f) Q. Li, C. W. Liskey and J. F. Hartwig, J. Am. Chem. Soc., 2014, 136, 8755-8765; (g) N. Ursinyova, R. B. Bedford and T. Gallagher, Eur. J. Org. Chem., 2016, 673-677.

17 For reports on the biological activities of $\beta$ aminoethylboronates, see: $(a)$ A. S. Gorovoy, O. Gozhina, J.-S. Svendsen, G. V. Tetz, A. Domorad, V. V. Tetz and T. Lejon, J. Pept. Sci., 2013, 19, 613-618; (b) A. S. Gorovoy, O. V. Gozhina, J. S. Svendsen, A. A. Domorad, G. V. Tetz, V. V. Tetz and T. Lejon, Chem. Biol. Drug Des., 2013, 81, 408-413.

18 Recently, Ni-catalyzed benzylic $\mathrm{C}\left(\mathrm{sp}^{3}\right)-\mathrm{N}$ borylation of benzylammonium triflates has been reported: (a) H. Zhang, S. Hagihara and K. Itami, Chem.-Eur. J., 2015, 21, 16796-16800; (b) C. H. Basch, K. M. Cobb and M. P. Watson, Org. Lett., 2016, 18, 136-139; (c) J. Hu, H. Sun, W. Cai, X. Pu, Y. Zhang and Z. Shi, J. Org. Chem., 2016, 81, 14-24.

19 (a) T. Ishiyama, T. Ahiko and N. Miyaura, Tetrahedron Lett., 1996, 37, 6889-6892; (b) T. Ahiko, T. Ishiyama and N. Miyaura, Chem. Lett., 1997, 26, 811-812; (c) S. Sebelius, O. A. Wallner and K. J. Szabó, Org. Lett., 2003, 5, 3065-3068. 20 (a) H. Ito, C. Kawakami and M. Sawamura, J. Am. Chem. Soc., 2005, 127, 16034-16035; (b) H. Ito, S. Ito, Y. Sasaki, K. Matsuura and M. Sawamura, J. Am. Chem. Soc., 2007, 129, 14856-14857.

21 (a) C.-T. Yang, Z.-Q. Zhang, H. Tajuddin, C.-C. Wu, J. Liang, J.-H. Liu, Y. Fu, M. Czyzewska, P. G. Steel, T. B. Marder and L. Liu, Angew. Chem., Int. Ed., 2012, 51, 528-532; (b) H. Ito and K. Kubota, Org. Lett., 2012, 14, 890-893; (c) A. S. Dudnik and G. C. Fu, J. Am. Chem. Soc., 2012, 134, 10693-10697; (d) S. K. Bose, K. Fucke, L. Liu, P. G. Steel and T. B. Marder, Angew. Chem., Int. Ed., 2014, 53, 17991803; (e) T. C. Atack, R. M. Lecker and S. P. Cook, J. Am. Chem. Soc., 2014, 136, 9521-9523; (f) R. B. Bedford, P. B. Brenner, E. Carter, T. Gallagher, D. M. Murphy and D. R. Pye, Organometallics, 2014, 33, 5940-5943.

22 For detailed information about the effects of the reaction conditions on yields and product distributions, see the ESI $\dagger$ 
23 (a) M. R. Netherton and G. C. Fu, Angew. Chem., Int. Ed., 2002, 41, 3910-3912; (b) J. H. Kirchhoff, M. R. Netherton, I. D. Hills and G. C. Fu, J. Am. Chem. Soc., 2002, 124, 13662-13663; (c) I. D. Hills, M. R. Netherton and G. C. Fu, Angew. Chem., Int. Ed., 2003, 42, 5749-5752.

24 J. Johnson and T. Rovis, Angew. Chem., Int. Ed., 2008, 47, 840-871.

25 (a) H. F. Bettinger, M. Filthaus, H. Bornemann and I. M. Oppel, Angew. Chem., Int. Ed., 2008, 47, 4744-4747; (b) S. Bagherzadeh and N. P. Mankad, J. Am. Chem. Soc., 2015, 137, 10898-10901.

26 For a review on the cross coupling of alkyltrifluoroborates, see: G. A. Molander, J. Org. Chem., 2015, 80, 7837-7848.

27 T.-S. Mei, H. H. Patel and M. S. Sigman, Nature, 2014, 508, 340-344.

28 (a) J. D. Scott and R. M. Williams, Chem. Rev., 2002, 102, 1669-1730; (b) K. W. Bentley, Nat. Prod. Rep., 2006, 23, 444-463.

29 L. Zhang, Z. Zuo, X. Leng and Z. Huang, Angew. Chem., Int. Ed., 2014, 53, 2696-2700.

30 L. K. Lukanov, A. P. Venkov and N. M. Mollov, Synthesis, 1987, 204-206.

31 D. M. Norton, E. A. Mitchell, N. R. Botros, P. G. Jessop and M. C. Baird, J. Org. Chem., 2009, 74, 6674-6680.

32 E. A. Mitchell and M. C. Baird, Organometallics, 2007, 26, 5230-5238.

33 A. D. Becke, Phys. Rev. A, 1988, 38, 3098-3100.

34 C. T. Lee, W. Yang and R. G. Parr, Phys. Rev. B: Condens. Matter Mater. Phys., 1988, 37, 785-789.

35 B. Miehlich, A. Savin, H. Stoll and H. Preuss, Chem. Phys. Lett., 1989, 157, 200-206.

36 S. Grimme, J. Antony, S. Ehrlich and H. Krieg, J. Chem. Phys., 2010, 132, 154104.

37 M. J. Frisch, G. W. Trucks, H. B. Schlegel, G. E. Scuseria, M. A. Robb, J. R. Cheeseman, G. Scalmani, V. Barone, B. Mennucci, G. A. Petersson, H. Nakatsuji, M. Caricato, X. Li, H. P. Hratchian, A. F. Izmaylov, J. Bloino, G. Zheng, J. L. Sonnenberg, M. Hada, M. Ehara, K. Toyota, R. Fukuda, J. Hasegawa, M. Ishida, T. Nakajima, Y. Honda, O. Kitao, H. Nakai, T. Vreven, J. A. Montgomery Jr, J. E. Peralta, F. Ogliaro, M. Bearpark, J. J. Heyd, E. Brothers, K. N. Kudin, V. N. Staroverov, R. Kobayashi, J. Normand, K. Raghavachari, A. Rendell, J. C. Burant, S. S. Iyengar, J. Tomasi, M. Cossi, N. Rega, J. M. Millam, M. Klene, J. E. Knox, J. B. Cross, V. Bakken, C. Adamo, J. Jaramillo, R. Gomperts, R. E. Stratmann, O. Yazyev, A. J. Austin, R. Cammi, C. Pomelli, J. W. Ochterski, R. L. Martin, K. Morokuma, V. G. Zakrzewski, G. A. Voth, P. Salvador, J. J. Dannenberg, S. Dapprich, A. D. Daniels, Ö. Farkas, J. B. Foresman, J. V. Ortiz, J. Cioslowski and
D. J. Fox, Gaussian 09, Revision D.01, Gaussian, Inc, Wallingford, CT, 2009.

38 A. V. Marenich, C. J. Cramer and D. G. Truhlar, J. Phys. Chem. $B, 2009,113,6378-6396$.

39 P. Fuentealba, H. Preuss, H. Stoll and L. Von Szentpály, Chem. Phys. Lett., 1982, 89, 418-422.

40 T. H. Dunning Jr and P. J. Hay, in Modern Theoretical Chemistry: Methods of Electronic Structure Theory, ed. H. F. Schaefe, Plenum, New York, 1977, vol. 3, pp. 1-28.

41 R. Ditchfield, W. J. Hehre and J. A. Pople, J. Chem. Phys., 1971, 54, 724-728.

42 W. J. Hehre, R. Ditchfield and J. A. Pople, J. Chem. Phys., 1972, 56, 2257-2261.

43 P. C. Hariharan and J. A. Pople, Theor. Chim. Acta, 1973, 28, 213-222.

44 M. M. Francl, W. J. Pietro, W. J. Hehre, J. S. Binkley, M. S. Gordon, D. J. DeFrees and J. A. Pople, J. Chem. Phys., 1982, 77, 3654-3665.

45 T. H. Dunning Jr, J. Chem. Phys., 1989, 90, 1007-1023.

46 R. A. Kendall, T. H. Dunning Jr and R. J. Harrison, J. Chem. Phys., 1992, 96, 6796-6806.

47 D. E. Woon and T. H. Dunning Jr, J. Chem. Phys., 1993, 98, 1358-1371.

48 S. Maeda, T. Taketsugu and K. Morokuma, J. Am. Chem. Soc., 2015, 137, 3433-3445.

49 S. Maeda and K. Morokuma, J. Chem. Phys., 2010, 132, 241102.

50 S. Maeda and K. Morokuma, J. Chem. Theory Comput., 2011, 7, 2335-2345.

51 S. Maeda, K. Ohno and K. Morokuma, Phys. Chem. Chem. Phys., 2013, 15, 3683-3701.

52 S. Dapprich, I. Komáromi, K. S. Byun, K. Morokuma and M. J. Frisch, J. Mol. Struct.: THEOCHEM, 1999, 461-462, 1-21.

53 T. Vreven, K. S. Byun, I. Komáromi, S. Dapprich, J. A. Montgomery, K. Morokuma and M. J. Frisch, J. Chem. Theory Comput., 2006, 2, 815-826.

54 T. Vreven and K. Morokuma, J. Comput. Chem., 2000, 21, 1419-1432.

55 F. Maseras and K. Morokuma, J. Comput. Chem., 1995, 16, 1170-1179.

56 T. Matsubara, S. Sieber and K. Morokuma, Int. J. Quantum Chem., 1996, 60, 1101-1109.

57 M. Svensson, S. Humbel, R. D. J. Froese, T. Matsubara, S. Sieber and K. Morokuma, J. Phys. Chem., 1996, 100, 19357-19363.

58 P. J. Hay and W. R. Wadt, J. Chem. Phys., 1985, 82, 270-283. 59 W. R. Wadt and P. J. Hay, J. Chem. Phys., 1985, 82, 284-298. 60 P. J. Hay and W. R. Wadt, J. Chem. Phys., 1985, 82, 299-310. 61 K. Morokuma, J. Chem. Phys., 1971, 55, 1236-1244.

62 K. Kitaura and K. Morokuma, Int. J. Quantum Chem., 1976, 10, 325-340. 